SPAL 30.2 $(2021)$

\section{4-102}

ISSN: $1133-4525$

ISSN-e: 2255-3924

FECHA RECEPCIÓN

07/12/2020

FECHA ACEPTACIÓN

08/02/2021

\title{
Ritualidad en el área de servicio de la cueva santuario del oppidum de Giribaile
}

RITUALITY IN THE SERVICE AREA OF THE SANCTUARY-CAVE OF THE GIRIBAILE OPPIDUM

\section{María Alejo Armijo}

Investigadora postdoctoral en el Instituto Universitario de Investigación en Arqueología Ibérica, Universidad de Jaén

maa00014@red.ujaen.es (1) 0000-0002-4286-1592 P AAB-5575-2019

(Responsable correspondencia)

\section{Luis María Gutiérrez Soler}

Catedrático de Universidad en el Instituto Universitario de Investigación en Arqueología Ibérica, Universidad de Jaén.

Imsoler@ujaen.es (10) 0000-0002-1630-0468 P AAA-8703-2019

\section{Antonio Jesús Ortiz Villarejo}

Profesor Sustituto Interino. Facultad de Humanidades y Ciencias de la Educación. Departamento de Antropología, Geografía e Historia. Área de Historia Moderna. Universidad de Jaén.

ajvillar@ujaen.es (D) 0000-0001-9330-3040 P AAB-5586-2019

\section{José Antonio Alejo Sáez}

Personal Técnico de Apoyo programa MINECO en el Instituto Universitario de Investigación en Arqueología Ibérica, laboratorio de conservación y restauración de material arqueológico. Universidad de Jaén.

jaalejo@ujaen.es (1) 0000-0001-7895-0725

\section{José Antonio Riquelme Cantal}

Profesor Titular de Prehistoria del Departamento de Historia (Área de Prehistoria). Facultad de Filosofía y Letras. Universidad de Córdoba. jriquelme@uco.es (D) 0000-0002-1494-7217 P AAA-5622-2019

Resumen En el año 2014 se realizó la primera y, hasta el momento, única campaña de excavación en un centro de culto menor asociado a una ciudad en el territorio político de Cástulo. Su diseño sigue el esquema tradicional de cueva santuario abierta hacia el valle. La intervención en la primera terraza ha permitido documentar varios hogares, una plataforma de adobe, un asador votivo y un registro cerámico coherentes con una práctica ritual vinculada a la comensalidad. La progresiva transformación arquitectónica del área de servicio hacia una terraza abierta podría enmarcarse como parte del proceso de implantación de un sistema ciudadano. Estas novedades referidas a un santuario suburbano completan el significado de los grandes referentes territoriales de las cuevas de Collado de los Jardines y de Castellar.

Palabras Clave Protohistoria Mediterránea, Hierro II, Cultura Ibérica, Andalucía, Guadalquivir, arqueología del culto, paisaje sacro.

Abstract In 2014 was carried out the first and, to date, only archaeological excavation conducted in a minor worship center associated with a city in the political territory of Cástulo. Its design follows the traditional sanctuary-cave planning, opened towards the valley. The archaeological intervention on the first terrace has allowed us to document several hearts, an adobe platform, a votive iron roaster and a pottery record related to ritual practices linked to commensality. The continuous architectural transformation of the service area towards an open terrace may be framed in the citizenship process. This study about a suburban sanctuary improves the interpretation of the main territorial studies of the Collado de los Jardines and Castellar caves.

Keywords Mediterranean Protohistory, Iron Age II, Iberian Culture, Andalusia, Guadalquivir, Archaeology of Cult, sacred landscape.

Alejo Armijo, M., Gutiérrez Soler, L.M., Ortiz Villarejo, A. J., Alejo Sáez J. A. y Riquelme Cantal, J. A. (2021): "Ritualidad en el área de servicio de la cueva santuario del oppidum de Giribaile", Spal, 30.2, pp. 74-102. https://dx.doi.org/10.12795/spal.2021.i30.18 
SPAL 30.2

(2021)

74-102

ISSN: $1133-4525$

ISSN-e: 2255-3924

\section{INTRODUCCIÓN}

El oppidum de Giribaile (Vilches, Jaén), por su entidad, monumentalidad y posición geoestratégica, constituye un lugar clave en el diseño de la política territorial de Cástulo desde mitad del siglo IV a.C. En el año 2014 dieron comienzo las campañas de excavación en la meseta de Giribaile. Estas actuaciones han formado parte de un proyecto general de investigación a seis años, autorizado y financiado por la Junta de Andalucía. Éste ha aportado datos históricamente significativos que actualizan las propuestas de interpretación científica, basadas hasta ahora, exclusivamente, en trabajos de registro de colecciones de materiales en superficie en la vega del Guadalimar y en la misma meseta de Giribaile (Gutiérrez Soler et al., 1995; 1999; Gutiérrez Soler, 2002). La presente contribución se focaliza en la investigación del Área 6. La intervención tuvo lugar en la terraza que da acceso a una cueva.

\section{CONTEXTUALIZACIÓN DEL HALLAZGO E INVESTIGACIONES PREVIAS}

La cueva se localiza en la ladera sureste del castillo califal-almohade, en la denominada plataforma norte, lugar donde se plantea la existencia de una acrópolis (Gutiérrez Soler, 2009), y se abre hacia la vertiente del Guadalimar (fig. 1). El interés por intervenir en esta zona viene determinado por los indicios sobre la posible existencia de un santuario. Desde el siglo XIX (Góngora y Martínez, 1860, pp. 7), se vincula a la localización de exvotos ibéricos en "una depresión próxima a la torre árabe" (Domergue, 1987, p. 22; 1990, p. 169). Aspecto que ha continuado vivo en las tradiciones orales de las comunidades locales y en la recopilación realizada sobre estas figurillas votivas en la península ibérica, que incluye a Vilches como un punto clave en la red de santuarios de Cástulo (Nicolini, 1969).

Las últimas investigaciones centradas en el estudio de los exvotos procedentes del Fondo Arqueológico Ricardo Marsal Monzón (Ruiz Rodríguez y Rueda Galán, 2014) muestran un panorama renovado para el Alto Guadalquivir, especialmente al registrar un gran número de figuras votivas relacionadas con diferentes puntos repartidos por todo el territorio, que anteriormente no habían sido tenidas en cuenta. Estos nuevos contextos de sacralidad se han interpretado o bien como talleres en el interior de las ciudades o bien como centros de culto menor asociados a núcleos urbanos, aunque ambas propuestas no son excluyentes. En este estudio, Giribaile aparece clasificado como centro de culto menor, situándolo como el segundo de los oppida con mayor número de bronces, por detrás de Los Altos del Sotillo (Castellar), con 71 exvotos. Por el momento no se ha constatado ningún hallazgo in situ de estas figurillas de bronce.

Durante la campaña de micro-prospección realizada en la meseta de Giribaile en los años 2004 y 2005 (Gutiérrez Soler, 2010), se identificó, por primera vez, la ubicación exacta del abrigo rocoso que mencionaba el profesor Domergue (1987, p. 22) y comenzó a asentarse la base de la realidad arqueológica sobre la posible presencia de un espacio de culto en el oppidum de Giribaile. La aparente configuración topográfica en terraza, propia de los santuarios del territorio de Cástulo, reforzaba esta interpretación.

El muestreo arqueológico superficial realizado en esta primera terraza (Rueda Galán et al., 2008, p. 33), documentó una mezcla de materiales pertenecientes a diferentes periodos, que son evidencia de la amplitud y de la continuidad histórica de la ocupación de la meseta de Giribaile. Durante la excavación del año 2014, esta larga secuencia 
SPAL 30.2 $(2021)$

\section{4-102}

ISSN: $1133-4525$

ISSN-e: 2255-3924
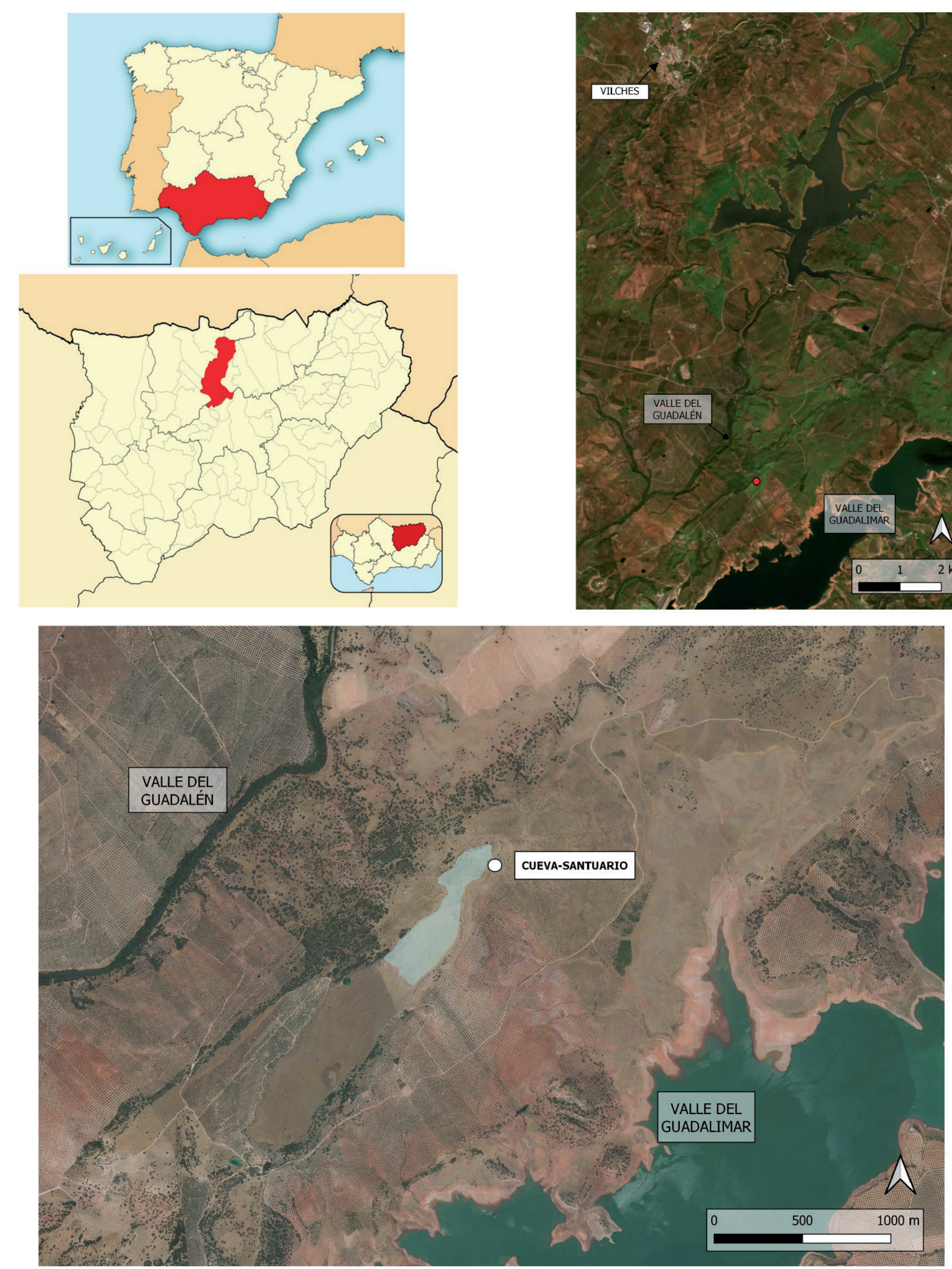

Figura 1. Ubicación de la cueva santuario de Giribaile sobre una fotografía. Fuente: Plan Nacional de Ortofotografía Aérea (PNOA). Ortofotos máxima actualidad del PNOA (www.ign.es/wms-inspire/pnoa-ma).

fue confirmada gracias al registro y documentación de niveles desde el periodo visigodo-emiral hasta alcanzar las construcciones más superficiales contemporáneas que delimitaban la terraza o cerraban la entrada de la cueva, además de fragmentos de cerámicas a mano procedentes del poblado de cabañas de la Edad del Bronce asentado en la meseta. 
SPAL 30.2

(2021)

74-102

ISSN: $1133-4525$

ISSN-e: 2255-3924

\section{DESARROLLO DE LA INVESTIGACIÓN}

\subsection{Ubicación del corte e incidencias}

La excavación del Área 6 tuvo lugar en el año 2014, abarcando una superficie total de casi $95 \mathrm{~m}^{2}$ y viene acotada por la propia pared de roca donde se abre la cueva, al Oeste, y por un muro que sirve de límite a la terraza, en el flanco Este. El proceso de excavación presentó varios inconvenientes. De entrada, no se pudo intervenir dentro de la cavidad debido al reducido espacio de circulación como consecuencia del hundimiento antiguo de parte de la bóveda. Más adelante, la campaña finalizó de una manera imprevista a causa del desprendimiento del farallón sobre la superficie intervenida en la propia terraza, afectando a la investigación de la Fase I.

\subsection{Análisis específico}

El Área 6 contó con análisis de los restos faunísticos y paleoambientales, a partir de la recogida directa o por flotación manual de muestras antracológicas y carpológicas. Además, se obtuvo una datación radiocarbónica, espuria a la fase de ocupación de la ciudad protohistórica. Finalmente, el estudio ceramológico ha contabilizado un total de 1.500 fragmentos, abarcando todos los periodos cronológicos. Para la clasificación de la cerámica correspondiente a época ibérica, en total 602 piezas diagnósticas, se han tomado como referencia las tipologías de Mata y Bonet (1992) y Pereira (1988).

Los análisis antracológico y carpológico fueron realizados por las doctoras Má Oliva Rodríguez Ariza y Eva Montes Moya, además de contar con la colaboración de Dña. Carmen Pradas, todas ellas adscritas al Laboratorio de Paleoambiente del Instituto Universitario de Investigación en Arqueología Ibérica de la Universidad de Jaén.

Los resultados de los análisis paleobotánicos se limitan a un número muy reducido de semillas, una característica común al resto de áreas de excavación intervenidas hasta el momento en Giribaile, y de carbones, siendo ocho los taxones identificados a partir del estudio antracológico. El informe sobre fauna lo llevó a cabo el Dr. José Antonio Riquelme proporcionando una colección dispersa de huesos en los niveles asociados a Cultura Ibérica, de los que no existe una prueba definitiva de que se trate de animales sacrificados como parte de un ritual, aunque en esta dirección parece apuntar la lectura del contexto de excavación.

Por lo que respecta a la cronología del sitio, ésta viene consignada por la cerámica y la sitúa grosso modo desde mitad del siglo IV a.C. hasta un momento indeterminado de finales del siglo III o la primera mitad del siglo II a.C., en consonancia con la propuesta más reciente para el horizonte de la ciudad protohistórica de Giribaile. Desgraciadamente, la única datación absoluta realizada hasta el momento sobre un carbón de Olea europaea de la UES 6083, ha proporcionado una fecha discordante con el nivel de procedencia, 1440 \pm 30 BP, 566-654 cal AD (Beta-490944; AMS C14: G14-6083).

\section{EVIDENCIA ESTRATIGRÁFICA}

Al inicio de la campaña la imagen de la fachada de la cueva para época ibérica se veía distorsionada por un muro de obra que tapaba parte de la entrada. El proceso de excavación 
SPAL 30.2 $(2021)$

\section{4-102}

ISSN: $1133-4525$ ISSN-e: 2255-3924

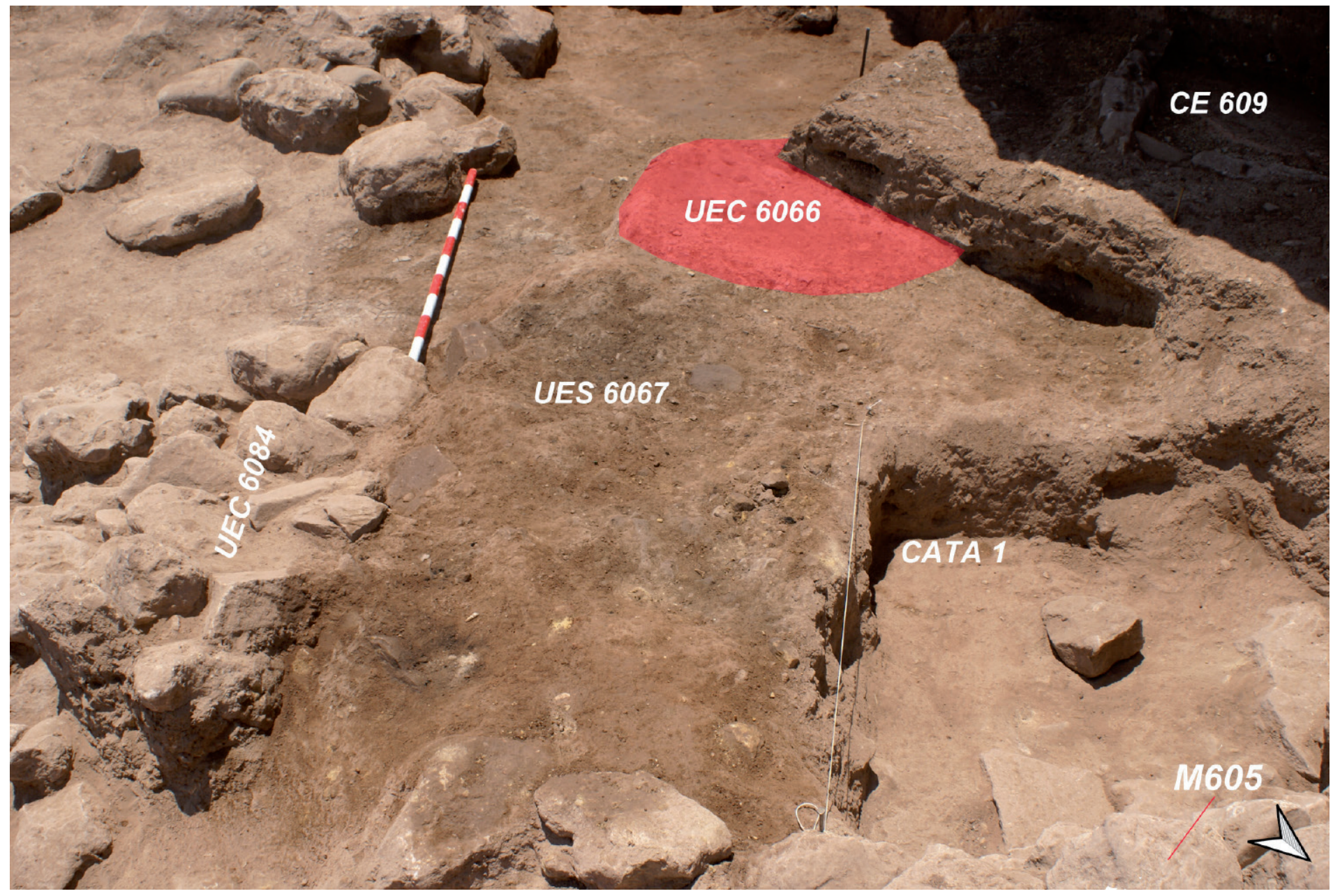

Figura 2. Área de servicio a la entrada de la cueva santuario de Giribaile con localización de uno de los hogares (CE 609), la mancha de carbón y ceniza (UES 6067) y la Cata 1.

ha permitido documentar variaciones en la inclinación natural de la terraza, que vierte hacia el valle del Guadalimar. Así pues, mientras en la zona Norte el sustrato geológico aflora casi en superficie, en la zona Sur, en el sector del Espacio 7, se alcanza una potencia estratigráfica de hasta 1,5 m.

La interrupción repentina de los trabajos imposibilitó completar la documentación del nivel de ocupación de la Fase I del santuario. No obstante, se pudo constatar, parcialmente, el momento de fundación en la Cata 1 (fig. 2), localizada junto a la entrada a la cueva. En este punto se registró la presencia fundacional del muro M605, que permaneció en uso a lo largo de las dos primeras fases del santuario.

La campaña de excavación ha permitido diferenciar tres fases constructivas en la primera terraza (fig. 3), más una cuarta, la inicial o de fundación, de la que tan sólo tenemos noticia a partir de una evidencia parcial registrada en el interior de la Cata 1. Al margen de esta última, de la que no se puede plantear una hipótesis de restitución, las dos primeras, que a partir de ahora serán denominadas como Fase I y Fase II, muestran un espacio cerrado (Fase I) o parcialmente obstruido (Fase II) al interior de la cueva. En la Fase III, la más reciente de todas ellas, la estructura se transforma, presentando un área abierta hacia el valle y destacan las construcciones adosadas a la línea de fachada de la cueva: el Espacio 7 y la plataforma de adobe.

\subsection{Fase I}

En el flanco Este se documentó el único muro que delimita la terraza (M603), el cual aprovecha, en parte, el afloramiento superficial de roca que forma el sustrato geológico (UEC 6074). El muro tiene una longitud aproximada de $17 \mathrm{~m}$ y define un espacio rectangular 
SPAL 30.2

(2021)

\section{4-102}

ISSN: $1133-4525$

ISSN-e: 2255-3924
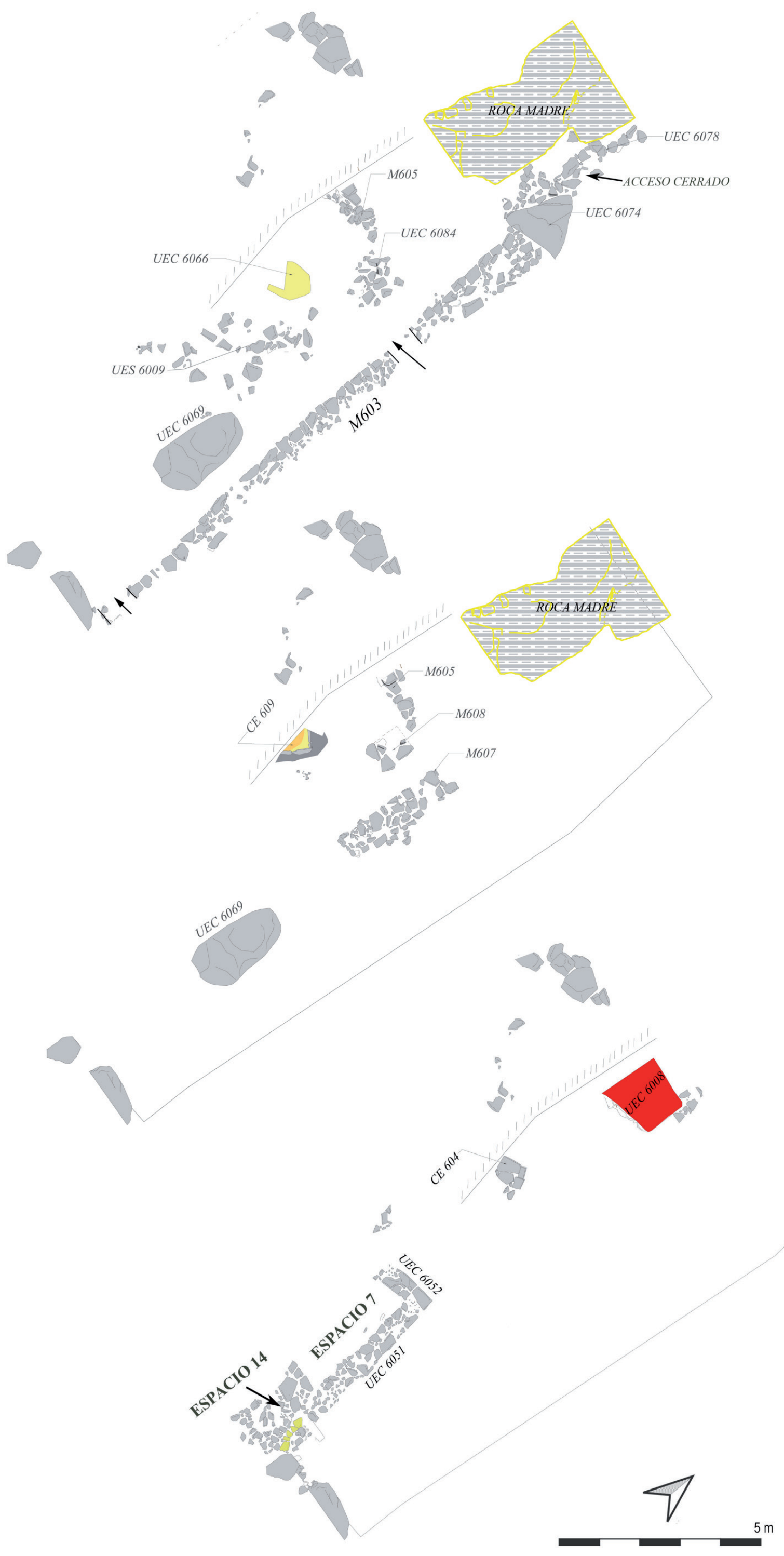

Figura 3. Cueva santuario de Giribaile. Articulación del espacio construido en la Fase I, Fase II y Fase III. 
SPAL 30.2

$(2021)$

74-102

ISSN: 1133-4525

ISSN-e: 2255-3924
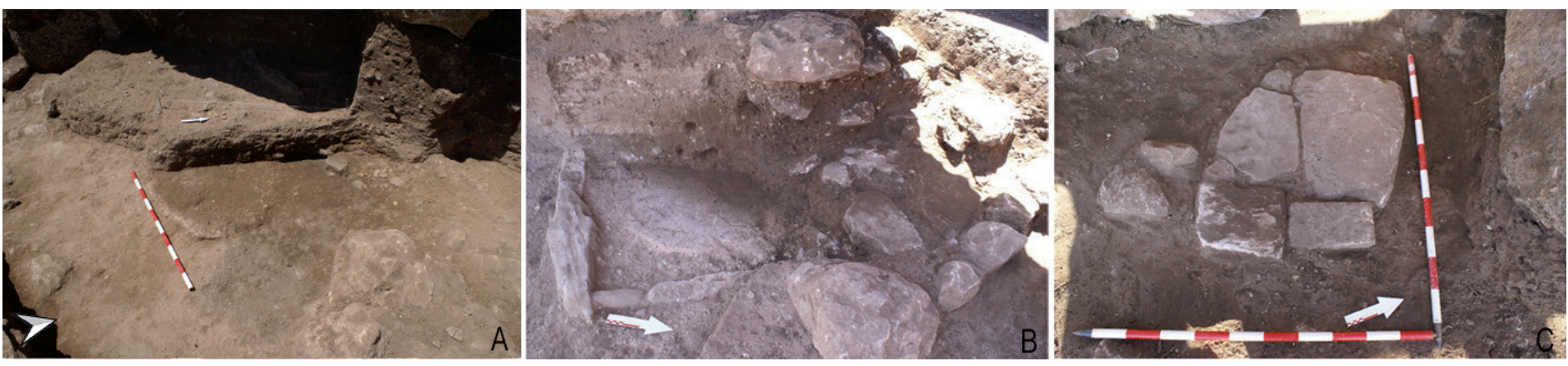

Figura 4. Placas de hogar (UEC 6066 y CE 609, adscritas a la Fase I y Fase II) y memoria del rito (CE 604, asociada a la Fase III).

cuya anchura oscila entre los 3 y los 3,7 m. Está fabricado con mampostería de mediano y pequeño tamaño, conservando en buen estado la cara interior, mientras que la línea exterior se ha perdido a causa de la erosión del terreno. Su anchura se calcula en torno a los módulos de $54060 \mathrm{~cm}$, que son cánones habituales de medida para la definición de muros de carga y medianerías en contextos cronológicos similares excavados recientemente en la propia meseta de Giribaile, como el Área 11 (Ortiz Villarejo et al., 2020a) y el Área 3 (Ortiz Villarejo et al., 2020b). Pudo tratarse de un muro bajo, a modo de cerca de piedra, que no impidiera completamente la visibilidad desde el exterior, aunque el derrumbe del alzado no puede calcularse al haberse perdido ladera abajo.

Del muro de cierre sólo se conserva una hilada, a pesar de lo cual han podido identificarse los tres accesos originales. El primero en la zona Sur, limitado por el afloramiento de roca. El segundo en la parte central, facilitando una entrada directa al área de servicio donde se documenta la superposición de los hogares, y un tercero al Norte, que se ciega posteriormente con un amontonamiento de piedra (UEC 6078). La entrada principal se corresponde con una simple interrupción en el muro y en el sector Norte, ésta se practicaría a través de un corredor oblicuo flanqueado por la roca madre y el afloramiento (UEC 6074) reaprovechado en la construcción del muro, mientras que al Sur el acceso tiene como límite un espacio de roca natural recortada. La circulación interior dentro de la terraza queda limitada, en el sector meridional, por un gran bloque de piedra (UEC 6069) in situ del que se puso al descubierto unos $2 \mathrm{~m}$ de longitud y $50 \mathrm{~cm}$ de alto, y que reducía la movilidad a un estrecho pasillo de unos $60 \mathrm{~cm}$ de ancho, que corría paralelo al muro de cierre (M603).

La placa de hogar UEC 6066 (fig. 4a) juega un papel central en la entrada de la cueva, conformando un espacio de uso comunal del fuego. La placa rubefactada, de tendencia circular, presenta un diámetro de $80 \mathrm{~cm}$, levantada sobre una base de piedras de pequeño tamaño.

\subsection{Fase II}

El paso a la Fase II define un cambio importante en el diseño de lo que más tarde caracterizaremos como área de servicio que antecede a la cueva santuario, sustituyendo el concepto de terraza arquitectónica por una entrada abierta parcialmente. El criterio de liminalidad viene ahora determinado por el muro M607. Se trata de una construcción individualizada, que recuerda la orientación del ya desaparecido M603 y que se alinea con el afloramiento de roca UEC 6069. Presenta unas dimensiones aproximadas de 60 $\mathrm{cm}$ de ancho por casi $3 \mathrm{~m}$ de largo. Pudo actuar como un poyo o banco corrido exento, 
SPAL 30.2

$(2021)$

74-102

ISSN: $1133-4525$

ISSN-e: 2255-3924 aunque también como un antemural, cuya función fuera obstaculizar el acceso directo a la entrada de la cueva, protegiendo junto al muro M605, el hogar CE 609 y la agrupación de piedras M608 que, tal vez, conformaran la base de un enlosado de forma cuadrada. La construcción M607 regulariza el límite que tan sólo se intuía en la agrupación caótica de piedras (UEC 6084), conjuntamente con la UES 6009, para la Fase I. En este supuesto, podría actualizar la función que cumplía una construcción anterior, ya amortizada, mientras que el muro M605 continúa actuando como parteluz del espacio a la entrada de la cueva definiendo el área de servicio al Sur.

El hogar CE 609 (fig. 4b) presenta el aspecto de una placa de adobe delimitada por lajas de piedra que conforman un espacio de tendencia cuadrangular, que recuerda al publicado en la Moleta del Remei (Tarragona), que data de finales del siglo III a inicios el siglo II a.C. Junto a CE 609 se recuperó un asador de hierro de $35 \mathrm{~cm}$ de longitud, de sección cuadrangular y en forma de T. Esta clase de instrumentos se asocian, habitualmente, al prestigio y a la comensalidad (Bonet Rosado 2013, p. 393). Inmediatamente hacia el Norte, se registró un depósito de carbones y ceniza (UES 6067). Por desgracia su contenido no pudo ser vaciado a causa del cierre inesperado del área de excavación.

\subsection{Fase III}

La Fase III representa el último momento de actividad vinculado a la ciudad protohistórica. Se trata de una restructuración profunda del diseño de la terraza. Leída en términos de creencias, daría continuidad al concepto de santuario progresivamente abierto hacia el valle del Guadalimar, ya iniciado con anterioridad, en línea con la redefinición del espacio destinado a la celebración religiosa que se apunta tras el final de los conflictos de la segunda guerra púnica en los santuarios de Castellar y de Collado de los Jardines (Ruiz Rodríguez et al., 2013, p. 221). Este proceso de refundación fue cuidadosamente planificado y responde a nuevos criterios de organización social del culto colectivo. Los elementos construidos se desplazan ahora lateralmente en la línea de fachada de la pared de roca y se concentran en la zona Sur (Espacio 7 y Espacio 14) y en el área central del corte (CE 604 y UEC 6008).

La Fase II queda amortizada por la UES 6023, un potente nivel estratigráfico de tierra con acumulaciones puntuales de piedra, como ocurre en el ángulo Sureste del espacio excavado en la terraza (fig. 5). La formación de la UES 6023 (fig. 6) puede interpretarse a partir de un proceso natural o antrópico. En el primero de los casos, habría que asumir un lapsus de tiempo largo que permitiera formarse este depósito a partir del desmoronamiento y caída de grandes construcciones de tapiales y de una sedimentación lenta. El segundo escenario, más probable en el contexto histórico de la ciudad, remite a una acción premeditada por parte de la comunidad de amortizar este espacio y reconstruir el área de servicio fundando las construcciones sobre una plataforma nivelada con materiales de relleno. Tomando en cuenta la colección de cerámicas presente en la secuencia estratigráfica y también el periodo limitado de vida activo de la ciudad de Giribaile que, actualmente se estima entre mitad del siglo IV a.C. y mitad del siglo II a.C., la segunda opción cobra más fuerza. Este argumento asume, de antemano, que los constructores y usuarios del santuario son los miembros de la propia comunidad asentada en la meseta.

La UES 6023 se extiende por toda la superficie del corte y sobre ella se edifica el Espacio 7 (fig. 7) y se levantan tanto la plataforma de adobe (UEC 6008), como la memoria 
SPAL 30.2 $(2021)$

\section{4-102}

ISSN: $1133-4525$ ISSN-e: 2255-3924

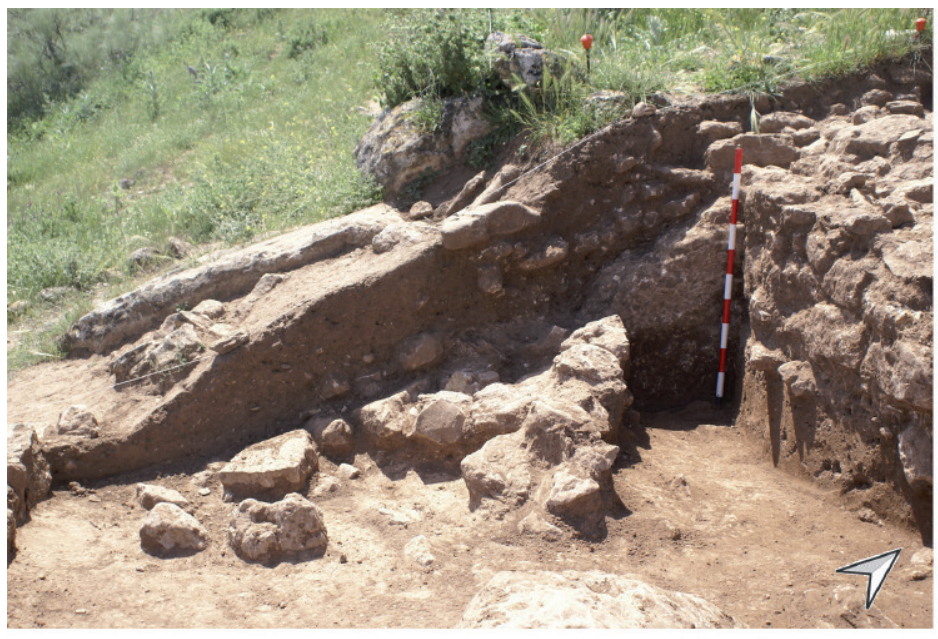

U.E.S. 6016

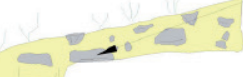

U.E.S. 6023 $1 \mathrm{~m}$

Figura 5. Perfil Sur del Área 6.

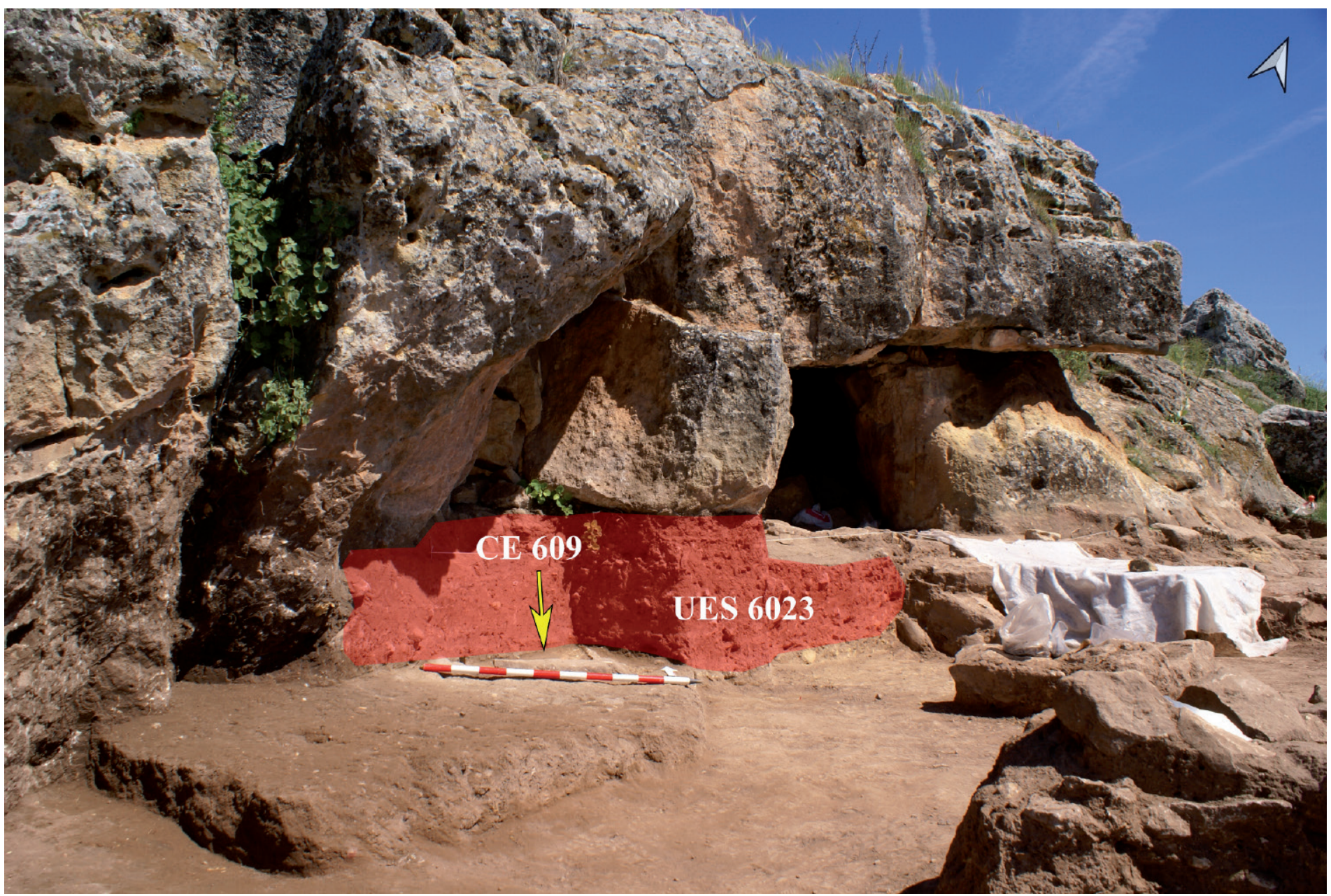

Figura 6. Cubrición de la Fase II del santuario con la UES 6023 y bloque de piedra caído a la entrada de la cueva santuario.

del rito (CE 604), un enlosado de piedras dispuesto a la entrada del santuario. El CE 604 (fig. 4c) cierra la serie de fuegos con un enlosado de siete piedras de diferente tamaño encajadas entre sí para crear una forma de tendencia rectangular de unos $80 \times 60 \mathrm{~cm}$, bajo la cual se documentó un nivel de tierra cenicienta. Se interpreta como un elemento simbólico, a modo de recordatorio del rito.

La plataforma de adobe (fig. 8) se dispone a la entrada de la cueva. El uso del adobe para subrayar el carácter sacro de una estancia o estructura es una constante en la Cultura Ibérica, tal y como se puede apreciar en la solería del departamento 14 de San Miguel de 
SPAL 30.2 (2021)

\section{4-102}

ISSN: $1133-4525$

ISSN-e: 2255-3924

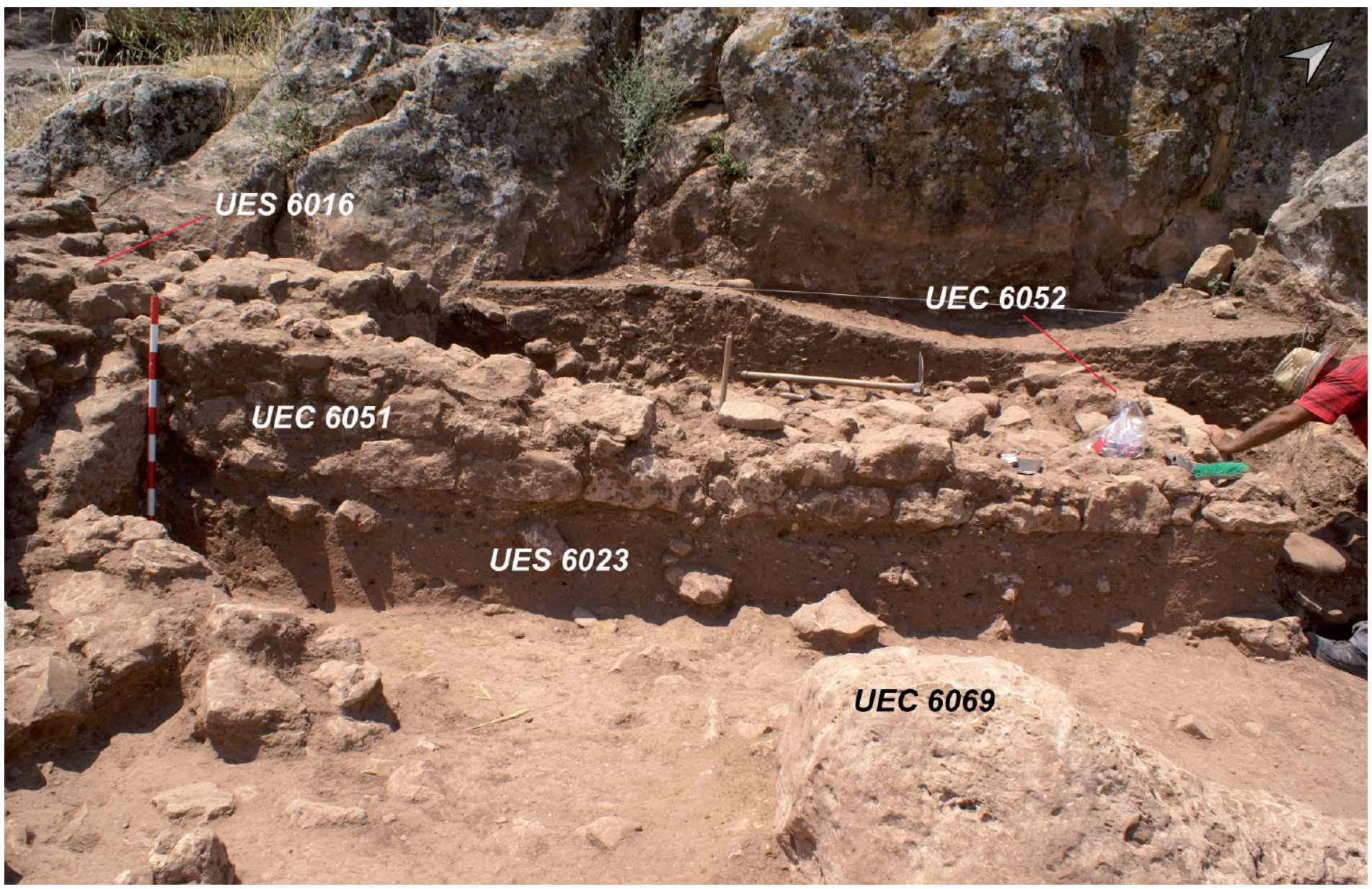

Figura 7. Proceso de trabajo en el sector meridional de la terraza de la cueva santuario, mostrando construcciones pertenecientes a las diferentes fases documentadas.

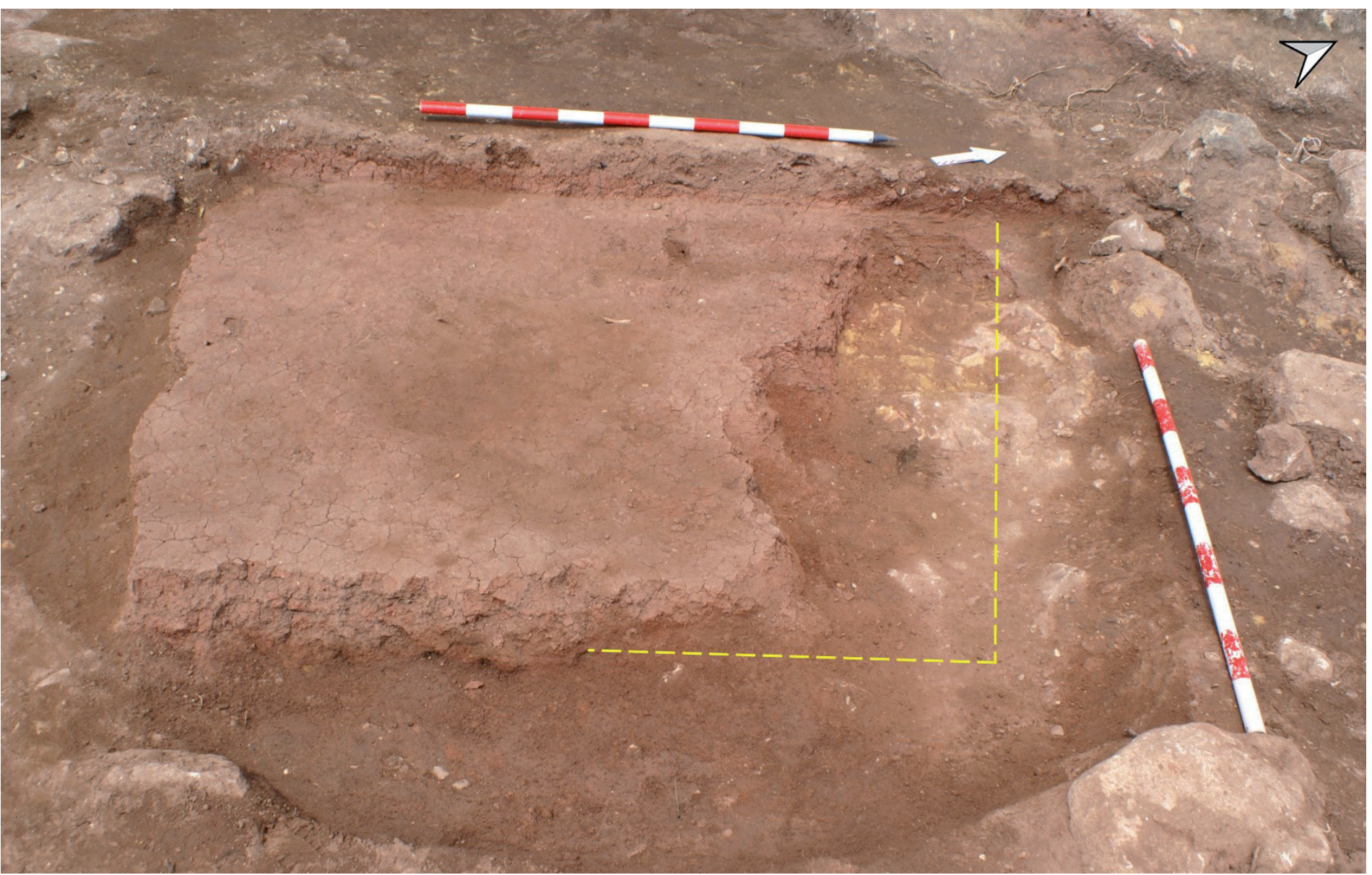

Figura 8. Plataforma de adobe (UEC 6008, adscrita a la Fase III).

Liria (Seco Serra, 2010, pp. 171-172), en altares más elaborados como en el poblado ibérico de El Oral (San Fulgencio, Alicante) (Abad Casal y Sala Sellés, 1993, p. 177), en el Parque Infantil de Tráfico de Elche (Ramos Fernández y Ramos Molina, 1992, p. 25; Castelo Ruano, 1995), en la última fase de Carmona, Sevilla (Belén y Escacena, 1997, p. 108), en la estancia 100 
SPAL 30.2

$(2021)$

74-102

ISSN: $1133-4525$

ISSN-e: 2255-3924 de El Turuñuelo (Guareña, Badajoz) (Rodríguez González, 2017) o como se observa en otros elementos de carácter ritual como el vasar documentado en el santuario de Montemolín (Marchena, Sevilla) (Chaves y de la Bandera, 1984, p. 708) o elementos litúrgicos portátiles, como los recuperados en Sant Crstòfol en Mazaleón o en el santuario portuario de Coria del Río (Sevilla) (Bea Castaño et al., 2004, p. 54-55). En el caso de Giribaile, su ubicación resulta un hecho insólito para la Cultura Ibérica, dado que los ejemplos hasta ahora documentados siempre las sitúan dentro de los poblados, relacionadas con el ámbito doméstico (Valiente Cánovas, 1994, p. 171; Almagro Gorbea, 1999, p. 39; Celestino Pérez, 2001, p. 42), tal y como se observa en el santuario de El Cerrón (Illescas, Toledo), donde se documentaron una serie de hogares rectangulares de adobe y un banco o altar realizado en el mismo material, decorado con un bajorrelieve (Valiente Cánovas, 1994, p. 171; Almagro Gorbea, 1999, p. 39).

Este pódium presenta unas dimensiones de 1,4 m de largo por 1,3 m de ancho, con un alzado de $5 \mathrm{~cm}$ al Sur y $30 \mathrm{~cm}$ al Este. Su disposición en el límite de la cueva, el espacio entre lo divino y lo terrenal (Laneri, 2015, p. 7; Lafond y Michel, 2016, p. 10), le confiere un fuerte sentido ritual y sacro, tal vez como camino ceremonial restringido a la persona que debía oficiar. De aceptar que se trata de un altar realzado o de superficie (Ginouves y Guimier-Sorbets, 1991, p. 278), realizado en adobe y ubicado justo en la entrada a la cueva, recalcaría la sacralidad del lugar. Generalmente, los altares se caracterizan por presentar una proyección demasiado baja para sentarse, pero amplia para las funciones de adoración, postración ante la divinidad, así como la realización de libaciones y ofrendas (Battini, 2015, p. 176), aunque en este caso, se trata de un "altar vacío" (Delougaz y Lloyd, 1942) cuya funcionalidad no está definida aún, dado que no se halló ningún material ni recipiente in situ que especifique el tipo de rito que se hubiera podido realizar a la entrada de la cueva. Su ubicación exterior quizás pudiera explicarse por la posibilidad de quemar ofrendas a cielo abierto (De Polignac, 1995, pp. 16-17).

Al Sur del área de servicio, se localiza el Espacio 7. Se trata de una habitación bien delimitada por sus flancos Norte (UEC 6052) y Este (UEC 6051), formando entre ambos muros un ángulo recto. Al Sur, la estancia presenta un potente cierre que actúa como muro de carga y soporta el adosamiento de una plataforma de piedra, seguramente una segunda habitación, de la que sólo se tiene una constancia parcial, denominada como Espacio 14. La construcción debió presentar cierta envergadura, tal y como se puede deducir por la entidad del derrumbe de piedra que se corresponde con la UES 6016 (fig. 9a). Se extiende hacia el Este, siguiendo el declive natural de la pendiente, tal y como se observa en la secuencia estratigráfica que recoge la fig. 5, y también hacia el Norte, cubriendo la mayor parte del Espacio 7. Un tercer aspecto relevante, además del inusual grosor del muro Sur y del volumen de los derrumbes, es el estado diferencial de conservación del alzado de los muros que conforman el perímetro de la estancia, ya que en su ángulo Sureste alcanza una altura actual superior al medio metro (fig. 7).

En cuanto a la técnica de construcción del Espacio 7, los muros de mampostería no apoyan sobre la roca, sino que se levantan directamente sobre la UES 6023, un depósito de tierra mezclado con piedras sueltas (fig. 7), aportado con la intención de crear una plataforma horizontal que se extendía por toda la terraza. Por lo que respecta a las piedras empleadas en la construcción, éstas tienen un tamaño mediano, entendiendo como tal aquellos mampuestos que permiten encajar entre sí, para conformar las caras de un muro de $60 \mathrm{~cm}$ de ancho. La estancia presenta una planta de tendencia rectangular, que reduce progresivamente el espacio hacia el Oeste, con una longitud de poco más de $3 \mathrm{~m}$ medidos en la cara interior del muro Este. El cambio de aparejo, haciendo uso de una mayor proporción de piedra de pequeño tamaño, permite observar la presencia 
SPAL 30.2 (2021)

74-102

ISSN: $1133-4525$

ISSN-e: 2255-3924
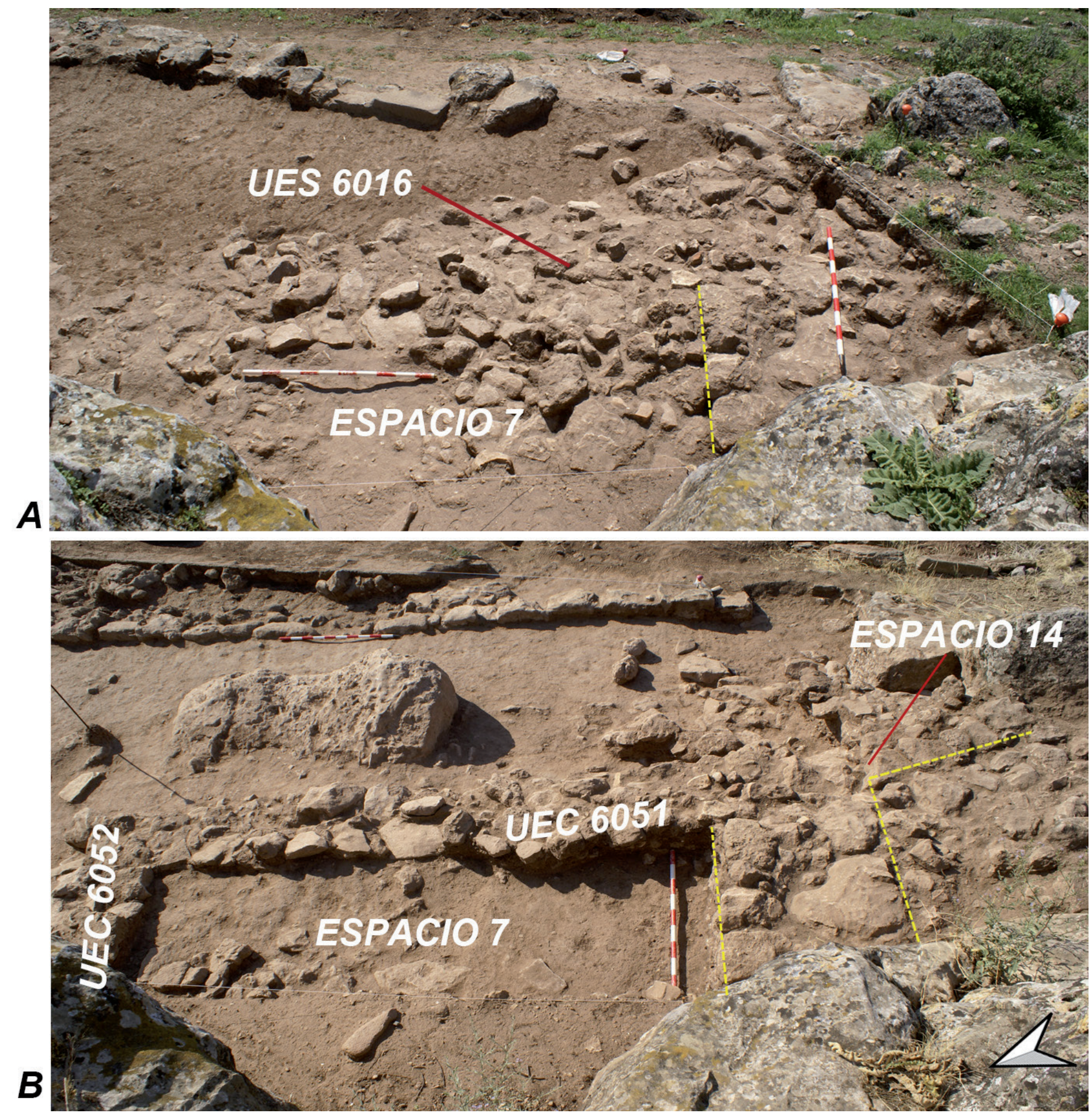

Figura 9. Momentos sucesivos de excavación del Espacio 7. A. Antes de levantar el derrumbe. B. Planta final de excavación.

de un vano de $1 \mathrm{~m}$ de ancho junto al muro Sur (UEC 6051, fig. 3). Esta entrada original fue cegada, lo que provocó un leve retranqueo de la línea de fachada.

De la habitación se excavó $1 \mathrm{~m}$ de ancho, pero la interrupción repentina de la campaña de excavación no dio tiempo a eliminar el testigo estratigráfico (fig. 7). En cualquier caso, la proyección del muro Sur, que forma un ángulo de $82^{\circ}$ con el muro Este, crea un espacio que se va cerrando progresivamente. Del contenido interior de la habitación apenas queda registro, tan sólo parte del derrumbe del muro Sur, cubierto por niveles de sedimentación post-deposicionales que rellenan completamente la estancia, tal y como se puede observar en el testigo de la secuencia estratigráfica que aún se mantiene en el flanco Oeste del Espacio 7 (fig. 7). El contexto de excavación lleva a plantear una desocupación programada que dificulta la interpretación directa sobre su función, tal vez vinculada al sacrificio de animales. En la campaña de excavación tampoco fue posible identificar un suelo. Tal y como atestigua la fotografía cenital de la fig. 9b, la excavación en el interior del Espacio 7 concluyó al alcanzar el paquete de relleno formado por la tierra y las piedras que conforman la UES 6023. En cualquier 
SPAL 30.2

$(2021)$

74-102

ISSN: $1133-4525$

ISSN-e: 2255-3924 caso, debió de tratarse, probablemente, no de un pavimento de piedras planas, sino de un sencillo suelo de tierra batida.

El estado de conservación del Espacio 7 no permite definir el lugar de acceso al interior de la estancia en el segundo momento de uso, es decir, una vez que la entrada original ubicada junto al ángulo Sureste fue clausurada. Tomando en consideración la entidad del derrumbe generado por el alzado de piedra sobre el muro Sur del Espacio 7, la interpretación más sencilla sería pensar que el ingreso a la habitación se habría producido a una cierta altura a través del muro Norte (UEC 6052), aunque tampoco puede descartarse que se tratara de una habitación de culto cerrada, que no permitiera el acceso a pie llano a las personas encargadas de las funciones litúrgicas.

La presencia de habitaciones cerradas en santuarios urbanos se interpreta, habitualmente, a partir del material documentado en su interior que lo dota de un carácter especial (Bea Castaño et al., 2004, p. 56; Grau Mira, 1996, p. 115; Seco Serra, 2010, p. 171). Ejemplo de ello se observa en la construcción D del santuario de Montemolín (Marchena, Sevilla), con un enlosado de piedras planas (Chaves y de la Bandera, 1984) o una gran cantidad de cerámica acumulada como acontece en el santuario de El Amarejo (Bonete, Albacete) (Broncano Rodríguez y Alfaro Arregui, 1993, p. 136; Almagro Gorbea, 1999, p. 51). Los betilos votivos confieren a estas estancias la categoría de capilla o cella, tal y como es el caso de San Miguel de Liria (Seco Serra, 2010, pp. 171-172) o el santuario del Cerro de las Cabezas (Valdepeñas) (Benítez de Lugo Enrich y Moraleda Sierra, 2013). En otras ocasiones, las habitaciones que forman parte del complejo religioso se vinculan a actividades relacionadas con el culto, como el despiece del animal o la elaboración de exvotos, como se ha documentado en los santuarios del Alto Guadalquivir (Rueda Galán, 2011).

La acción de vaciar y tapiar de forma intencionada una estancia también se ha propuesto en el santuario del Cerro de las Cabezas, aunque no queda muy clara la intención en la interpretación final. De otra parte, en el santuario urbano de Atalayuelas (Fuerte del Rey) se documentó una habitación cerrada con escaso material asociado, interpretada como una cella o capilla para la divinidad; a pesar de que no se encontró ninguna evidencia significativa, no se descarta que este espacio estuviera destinado a albergar la imagen de una deidad en determinados momentos (Rueda Galán et al., 2015, p. 429), recordando el traslado estacional del betilo desde el adyton a su ubicación central en el corredor en el santuario de la Puerta del Sol en el oppidum de Puente Tablas (Ruiz Rodríguez et al., 2015).

Al quedar fuera del área de excavación, la campaña no ha permitido establecer su relación funcional con el Espacio 14, una construcción adosada al muro de cierre Sur del Espacio 7 documentada en planta sólo de forma parcial. La intervención se limitó a descubrir la alineación del muro de fachada que conectaba el ángulo Sureste del Espacio 7 con un afloramiento de roca próximo y a mantener el nivel de derrumbe correspondiente a la UES 6016 (fig. 9), es decir, no se definieron los límites del Espacio 14 en todo su perímetro ni se rebajó su contenido interior, que aún permanece sellado, a falta de obtener una nueva autorización.

Desde un punto de vista estratigráfico, la UES 6016 (fig. 5), documentada en el ángulo Sureste del área de excavación, se corresponde con el nivel de derrumbe del alzado de las paredes de los Espacios 7 y 14 y, por tanto, debe ser interpretada como el nivel de abandono y ruina de las últimas construcciones edificadas en el santuario, una vez que este fue abandonado. Esta unidad sedimentaria fue retirada convenientemente para facilitar la excavación del Espacio 7, pero no así del Espacio 14 donde aún permanece in situ. 
SPAL 30.2 (2021)

\section{4-102}

ISSN: $1133-4525$ ISSN-e: 2255-3924

\section{SIGNIFICADO RITUAL DE LOS REGISTROS DE CULTURA MATERIAL}

La elección precisa de este lugar como centro de culto debió estar motivada por tres factores principales: su proximidad al palacio, su dominio como referencia visual en el paisaje y, posiblemente también por una orientación astronómica vinculada con episodios concretos del movimiento solar durante el año, tomando en consideración los momentos en los que el sol incide sobre la zona de los hogares antes de entrar a través de un hueco artificial tallado a modo de ventana en la parte norte del farallón y hacerse presente en el interior de la misma cueva. El hundimiento interior de la bóveda impide plantear este estudio por el momento. Se trata de un fenómeno ampliamente documentado en los santuarios del levante peninsular e ibéricos de la provincia de Jaén, como la Cueva de La Lobera (Nicolini et al., 2004, p. 149; Ocharán Ibarra, 2017) o la recientemente excavada Puerta del Sol del oppidum de Puente Tablas (Ruiz Rodríguez et al., 2015).

En el caso de Giribaile, la cueva está orientada hacia el Sureste, abierta hacia el valle del Guadalimar, en el que se dispuso el grueso de los asentamientos estables vinculados al horizonte de ocupación de la ciudad establecida en la meseta. La mayor parte de estos lugares mantenían, por tanto, una comunicación visual directa con el santuario (fig. 10) que, actuaría, presumiblemente, como pantalla de una escenografía compleja en la que se anteponía al palacio ubicado en el extremo de la plataforma Norte, sintetizando un discurso del poder que expresa la unión indivisible entre lo político y lo sagrado, entrelazados como signos de identidad de la comunidad. Estos mecanismos de autorrepresentación de intangibles simbólicos complementarían la lectura del dispositivo de barrera de la fortificación y del monumento fundacional emplazado en la plataforma inferior, duplicando el valor propagandístico del mensaje de poder hacia la

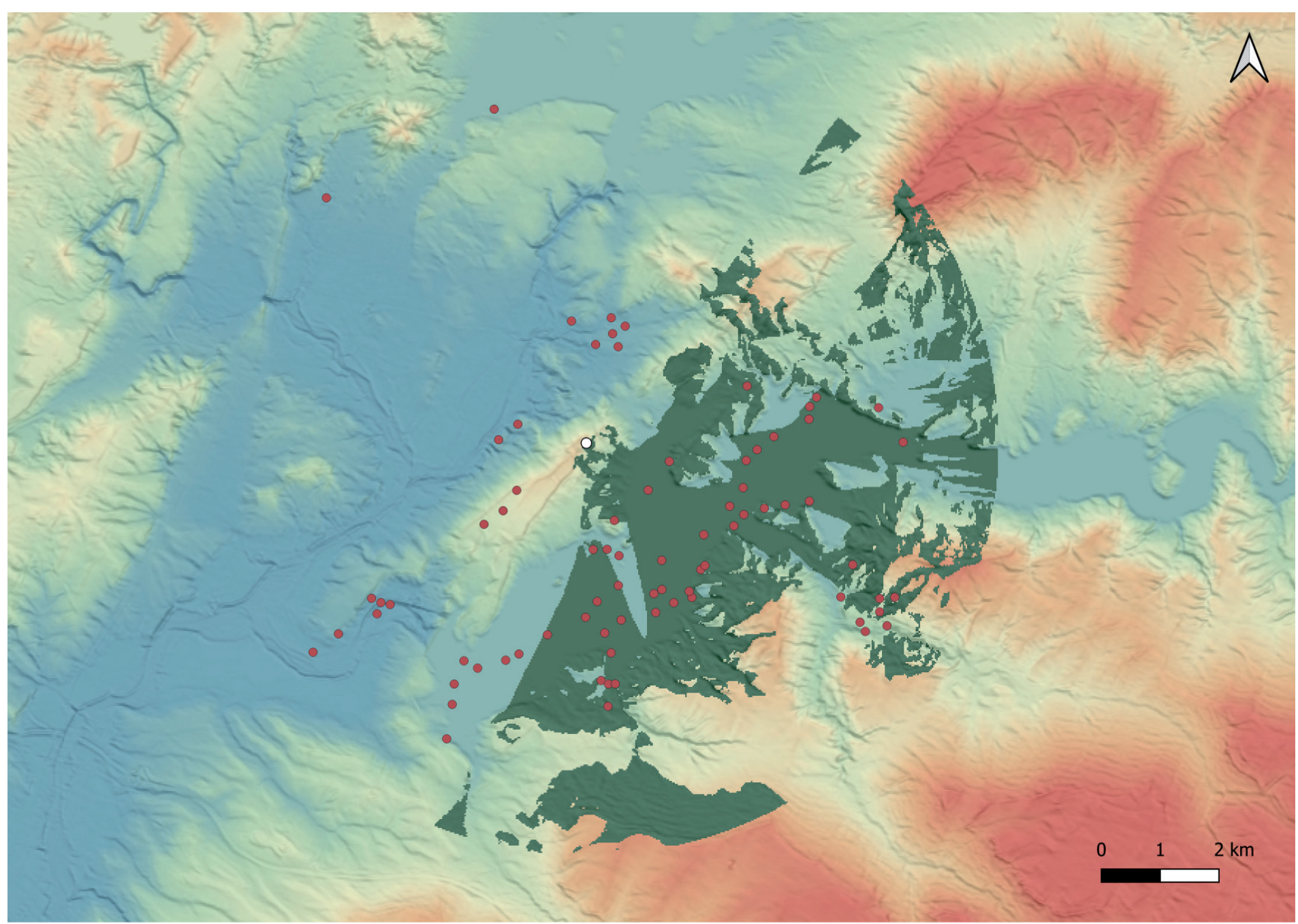

Figura 10. Análisis de la cuenca visual de la cueva santuario con relación a los asentamientos de su territorio de explotación económica directa. 
SPAL 30.2

(2021)

74-102

ISSN: $1133-4525$

ISSN-e: 2255-3924 vía que atravesaba las márgenes del Guadalén. De este modo, el santuario en cueva crea un discurso de autoconsumo dirigido hacia los habitantes de la comunidad local, desempeñando un importante papel en su vida social, que se complementa con los diseños monumentales del tramo principal de la fortificación y del monumento fundacional, proyectando la imagen exterior del poder de la ciudad. Esta propuesta de interpretación asume la existencia de un espacio privilegiado e individualizado en el espolón Norte de la meseta de Giribaile, al que al comienzo del artículo calificamos como acrópolis, donde se levanta el castillo y que, probablemente, sirviera de ubicación anterior a la residencia de los régulos o príncipes durante la etapa protohistórica, aunque hasta el momento no ha sido posible intervenir aquí mediante una campaña de excavación arqueológica.

En una escala de interpretación próxima, habría que considerar la propia morfología de la fachada de la cueva como un elemento más de culto. Los hogares, como centro del área se servicio se dispusieron aparentemente bajo un gran bloque arqueado, hoy vencido. Además, debemos recordar la presencia del muro M605 como parteluz del acceso al interior de la cueva desde los momentos de fundación del santuario. A este respecto, un reciente estudio ha planteado la importancia de estudiar la apariencia externa de los santuarios rupestres (Ocharán Ibarra, 2017, pp. 697-700), dado que hay una serie de elementos que se repiten en cuevas del Sureste peninsular y de filiación fenicio-púnica, como es la división de la cavidad en dos espacios mediante una columna o pared de separación similar a un pilar, aspecto que se recoge en las fuentes clásicas (Hom. Od. XIII, 96-112). Al igual que se explica en otros casos alejados, como La Serreta, no resulta necesaria la monumentalización de la cueva, ya que destacaría en el paisaje la relación ciudad-santuario (Grau y Amorós, 2013).

Del análisis antracológico (tab. 1, ver Anexo), para los niveles correspondientes a la Fase I y Fase II se deduce que la terraza se concibe como un espacio abierto, ante la total falta de carbones de Pinus halepensis, ya que el pino carrasco ha sido constatado como la principal madera de construcción del armazón de vigas en el único espacio techado excavado hasta el momento en la meseta de Giribaile (Ortiz Villarejo et al., 2020b). Por el contrario, la presencia de cuatro muestras de madroño (Arbustus unedo) podría relacionarse, tal vez, con algún sombrajo provisional confeccionado con ramas. El resto de carbones parecen relacionarse con especies que proporcionan madera con un alto poder calorífico y perdurabilidad, ideales para su utilización como combustible en hogares domésticos o artesanales, predominando el lentisco (Pistacia lentiscus), como iniciador del fuego (Rodriguez Ariza, 2007) y el acebuche (Olea europaea), seguidos a distancia por el almendro y la encina y/o coscoja (Quercus ilex/coccifera).

En la secuencia de fuegos a la entrada de la cueva de Giribaile cada uno de ellos se adscribe a uno de los periodos de actividad del santuario, a saber, la UEC 6066 se asocia a la Fase I y el CE 609 se vincula a la Fase II, mientras que su memoria (CE 604) se relaciona con la Fase III. La reiteración de los hogares marca una misma pauta de ceremonias y su ubicación justo en la entrada de la cavidad define el uso dual de este tipo de santuarios rupestres (Ocharán Ibarra, 2017), donde hay una marcada diferencia entre el espacio destinado a la comunidad y a la divinidad, junto al corpus sacerdotal encargado de la deposición de ofrendas en el interior del santuario (Nicolini et al., 2004). Además, su localización frente al acceso principal a la terraza en la Fase I marca la centralidad de este lugar, identificado como área de servicio. Resulta difícil establecer cuáles serían las actividades precisas llevadas a cabo por la comunidad en este espacio sagrado, aparentemente en uso durante todo el periodo de vida de la antigua ciudad establecida en la meseta de Giribaile, y cómo se concretarían en el registro material, a pesar de que en 
SPAL 30.2

$(2021)$

74-102

ISSN: $1133-4525$

ISSN-e: 2255-3924 los últimos años han sido varios los lugares de culto excavados y publicados en el Alto Guadalquivir.

Tanto los santuarios vinculados a la ciudad, entre los que cabe citar Atalayuelas (Fuerte del Rey) o la Puerta del Sol (Puente Tablas), como los santuarios rupestres localizados en parajes naturales, incluyendo Collado de los Jardines (Santa Elena), Cueva de la Lobera (Castellar) o Pico del Águila (Orcera), presentan estancias y/o terrazas con una serie de elementos cultuales (hogares, bancos corridos, habitáculos, pórticos...), que no hacen sino subrayar el carácter multifuncional de las acciones que se llevan a cabo al exterior del santuario. En general, los registros arqueológicos muestran una clara diferencia entre las actividades previas, desarrolladas en un espacio concreto y próximo al santuario, y la propia deposición de las ofrendas. En el santuario urbano de la Puerta del Sol (Ruiz Rodríguez et al., 2015) y en las terrazas del santuario de la Cueva de la Lobera se practicaban actividades relacionadas con el despiece del animal o a la fabricación de exvotos (Rísquez Cuenca et al., 2015); sin embargo, no es una norma establecida, ya que en el recientemente excavado santuario extraurbano de la Piedra del Águila (Orcera), perteneciente al oppidum de Bujalamé (La Puerta de Segura), gran parte de la liturgia se llevó a cabo en el interior de la cueva a través de la quema de ofrenda en hogares rituales (Rueda Galán y Bellón Ruiz, 2016, p. 78).

En el caso de Giribaile y siguiendo las consideraciones de estudios antropológicos, la clara delimitación de la zona donde se suceden los fuegos rituales, en el espacio comprendido entre los muros M605 y M607 (para la Fase II) y anteriormente entre M605 y UEC 6084 (para la Fase I), convierte al fuego en el elemento por excelencia, bien como consagración de un lugar para su sacralización o bien como el centro de la vida doméstica (Negroni Catacchio et al., 2002, p. 118; Kaliff, 2011, p. 53). Tal y como plantea el enfoque etnoarqueológico de Dietler y Hayden (2001), se trataría de un espacio que no ha sido expresamente construido para el banquete, sino a través del banquete y cuanto más compleja es la elaboración arquitectónica/escenografía más se detalla el ritual, aunque por el momento resulta difícil precisar el tipo de prácticas concretas cuando el espacio de uso ha sido convenientemente amortizado. La superposición de los hogares y la plataforma de adobe a la entrada de la cueva (fig. 11) puede interpretarse como elemento cultual que implica una práctica de cohesión social de una comunidad a través de la comensalidad (Henson, 2011). La importancia de esta zona se manifiesta en la reiteración de los hogares en un mismo espacio, hecho que podría marcar una pauta ceremonial vinculada a la celebración de banquetes y al tratamiento previo de los alimentos, una actividad propia de las comunidades protohistóricas de Europa (Armada Pita, 2015, p. 123).

El contexto de excavación proporciona un número muy limitado de restos de fauna (tab. 2, ver Anexo), cinco huesos para la Fase I y un ejemplar, respectivamente, para la Fase II y la Fase III, alcanzando la cifra de diez para la interfaz entre la Fase II y la Fase III. Estos últimos podrían relacionarse con la amortización del hogar CE 609 de la Fase II, si aceptamos que la UES 6023 y la UES 6042 corresponden a un momento inmediatamente posterior a su último uso. El registro faunístico constata la presencia de ovis aries/capra hircus (ovicaprino) y sus domesticus (cerdo), compuesta por un número mínimo de individuos de un cerdo/jabalí y tres ovicaprinos. Durante las dos primeras fases los restos se concentran en torno a los hogares centrales, mientras que, en el último momento, destacan la presencia exclusiva de la mandíbula de un ovicaprino en el Espacio 7 (fig. 12). Por lo que respecta a la edad del sacrificio de la cabaña ovicaprina, predominan los animales adultos sobre el resto, sin constatarse ejemplares seniles. Esta cohorte 
SPAL 30.2 (2021)

\section{4-102}

ISSN: $1133-4525$ ISSN-e: 2255-3924

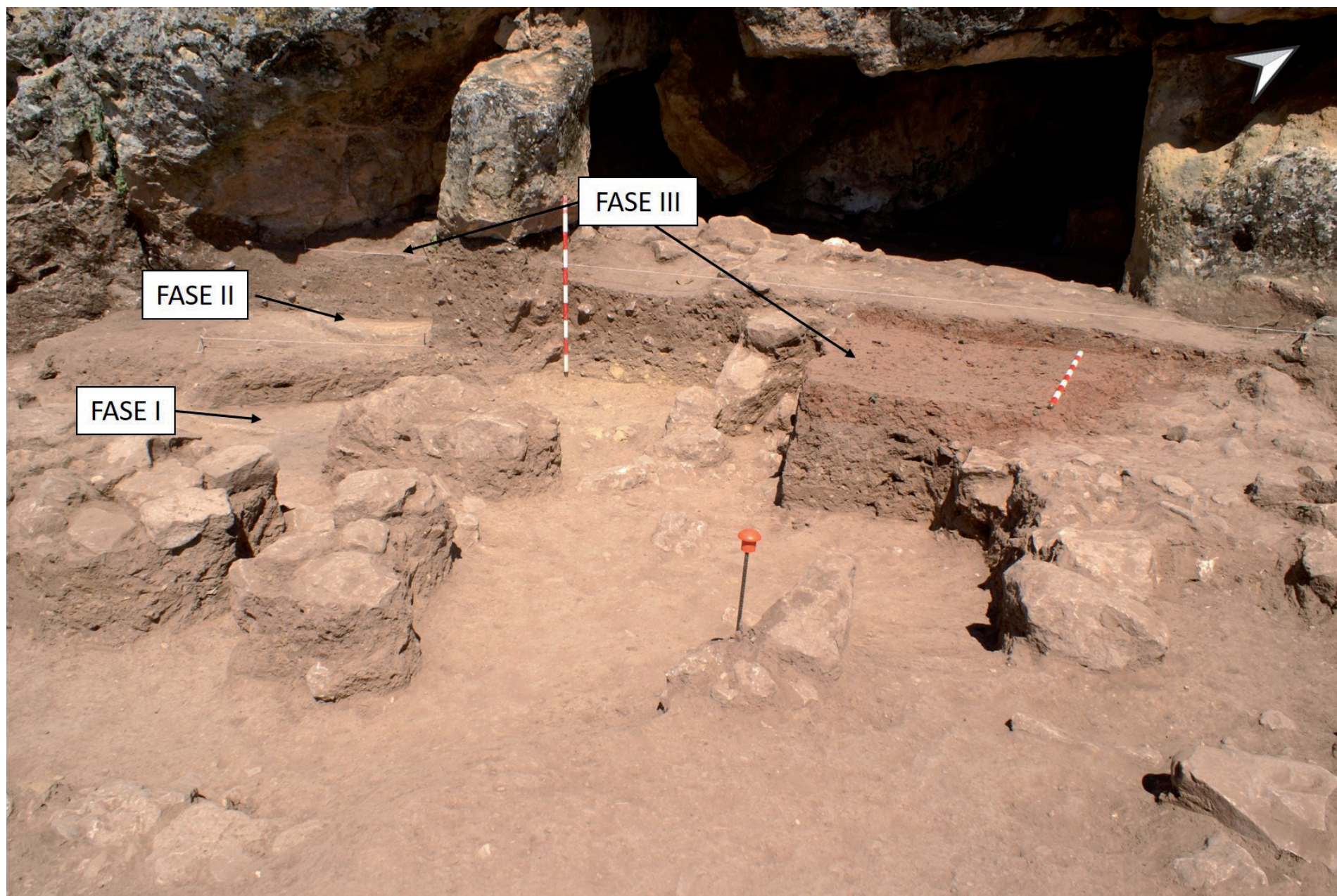

Figura 11. Superposición de hogares y plataforma de adobes en el área de servicio de la cueva santuario de Giribaile.
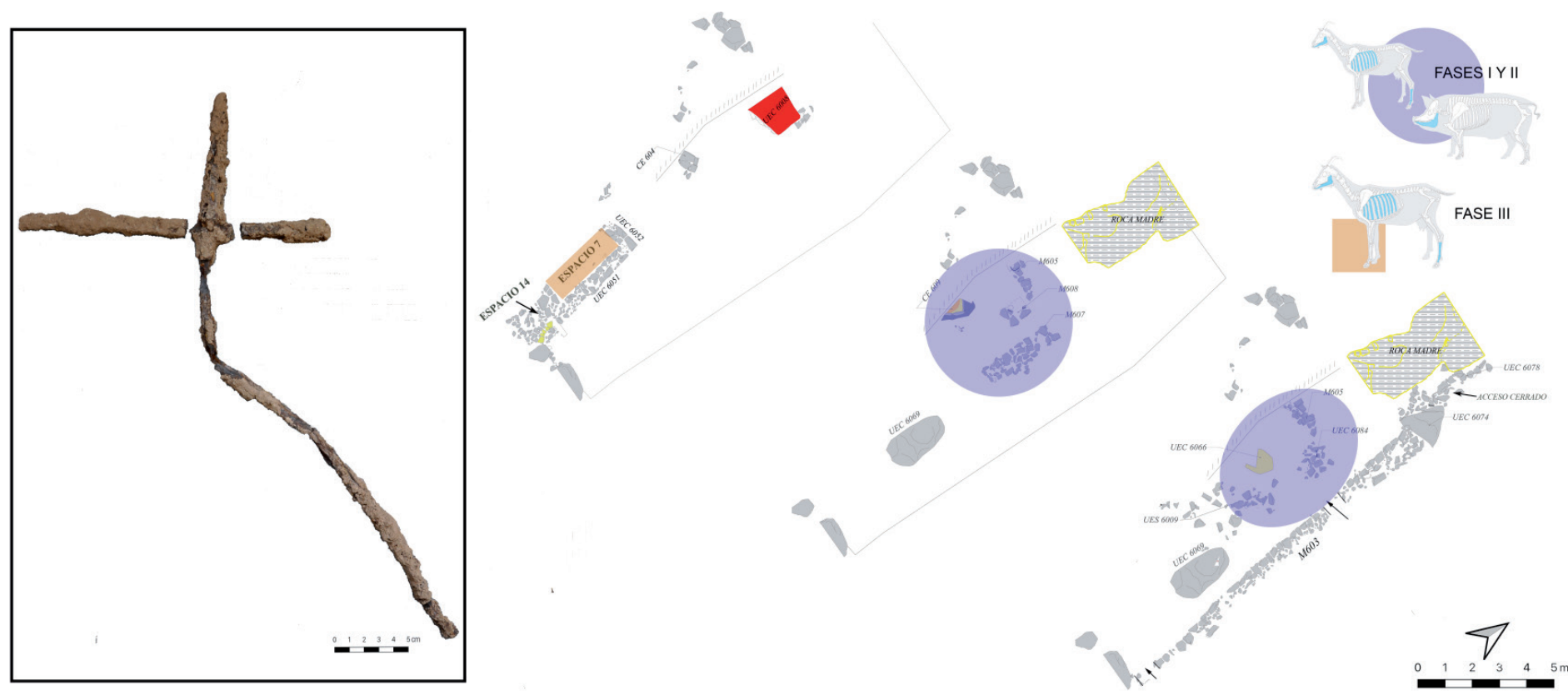

Figura 12. Distribución de la fauna en la primera terraza y asador votivo.

de edad presenta una destacada finalidad alimentaria, claramente enfocada hacia el aprovechamiento cárnico (Moreno García, 2011). Dentro de los taxones documentados correspondientes a la cabaña de cerdos, se encuentran representadas todas las cohortes de edad, pero destacan aquellos que aún no han alcanzado la edad adulta, que son los que se suelen ofrecer en los espacios de culto (Moreno García, 2011), de acuerdo a la noción de que las víctimas debían ser de primera calidad (Ekroth, 2014). En la fauna no se realiza ninguna observación particular respecto a evidencias de posible manipulación o procesamiento.

En cuanto a los grupos faunísticos documentados, la mayor parte de las piezas anatómicas identificadas corresponden a aquellas de bajo valor alimenticio, tibias y piezas 
SPAL 30.2

(2021)

\section{4-102}

ISSN: $1133-4525$

ISSN-e: 2255-3924 dentales (Ekroth, 2014, p. 500; Tortosa Rocamora et al., 2018, p. 319), algo propio del reparto de la víctima para la divinidad a la que se dirige el sacrificio y los oferentes que lo celebran. En el despiece, las ofrendas a la divinidad corresponden a aquellos trozos con un escaso valor alimenticio, mientras que las partes más nutritivas del animal son reservadas para el consumo humano. Atendiendo a los pocos datos faunísticos recuperados en el Área 6, se podría plantear la existencia de otra zona en la que se consumiría el alimento, que también podría ser llevado en pequeñas cestas a las casas o para la venta en lugares públicos (Ekroth, 2014), siendo únicamente la primera terraza la destinada a la preparación de los alimentos como ofrenda a la divinidad, algo que viene recalcado con la presencia de los hogares y del asador (Chaves Tristán et al., 1995, p. 321; Halstead y Isaakidou, 2004). En los santuarios de Cástulo se ha documentado este tipo de sacrificio, donde la carne se cocinaba y comía en el santuario, reservando una parte a la divinidad, que se ofrecía en un vaso; aunque las partes para la divinidad podían variar, en Las Atalayuelas (Fuerte del Rey) se constató la deposición de mandíbulas inferiores de cerdos en ollas de pequeño tamaño (Rueda Galán, 2012, p. 185).

Los resultados del análisis carpológico no ayudan a la interpretación de los actos de comensalidad, ya que sólo ha sido posible identificar tres semillas en total, dos cariópsides de trigo (Triticum aestivum/durum) y un fragmento de tallo de tipo caña (tallo phoaceae), ambos documentados en la UES 6013 (nivel post-ibérico). También hay que tener en cuenta que los contextos de deposición de las unidades sedimentarias reflejan la amortización programada de las áreas de actividad, con la sola excepción del respeto de los hogares; esta situación se observa muy bien a través de la dispersión caótica de materiales en las unidades de interfaces, condicionando por tanto el estudio espacial y las interpretaciones funcionales de las posibles dispersiones, ya que no se conservan los contextos de uso originales.

El otro gran factor de análisis contextual de la campaña de excavación, que acompaña a la fauna, se corresponde con el análisis estadístico de la cerámica (tab. 3); un elemento clave para poder aproximar las prácticas rituales vinculadas a la preparación de los alimentos destinados como ofrendas y/o para su consumo en esta área de servicio (Cazorla Martín y Celestino Pérez, 2008, p. 227). Como cabía esperar, en la primera terraza en los niveles asociados al uso del santuario (tab. 3 -ver Anexo- y fig. 13), predomina la vajilla de mesa (Grupo III) con un 44\%, especialmente formas abiertas, como platos (A.III.8) y cuencos (A.III.9). Entre estos últimos, los del tipo 16-D (Pereira Sieso, 1988), de borde exvasado, cuerpo semiesférico, con pie marcado y fondo hundido o plano, representan un $91 \%$ del total de los fragmentos, mientras que un $6 \%$ de los platos se corresponden con el tipo 17-B, de borde ancho y ligeramente carenado, con un diámetro comprendido entre 10 y $20 \mathrm{~cm}$. Los cuencos pueden ser usados tanto para beber como para contener alimento sólido (Niveau de Villedary y Mariñas, 2003, p. 24), pero, al mismo tiempo, su interpretación en contextos rituales podría asociarse a comidas comunales (Aparicio Pérez, 1997, p. 18) y libaciones (Rueda Galán, 2011, p. 237). La cerámica gris representa un significativo $9 \%$ del total de los fragmentos, correspondiendo un $2 \%$ a la tipología de cuenco, auténticas piezas diagnóstico del horizonte asociado al santuario de Castellar.

A pesar de la fragmentación del material, se ha podido realizar una aproximación al número mínimo de individuos a partir de los fondos de los recipientes cerámicos (Adroher Auroux et al., 2016), contabilizando 18 individuos de cerámica gris entre platos y cuencos. Por lo que respecta al otro gran grupo, conformado por la cerámica común y los grandes recipientes, se ha identificado la presencia de otros 18 individuos. Entre los grandes recipientes, pertenecientes al Grupo I y al Grupo II de la tipología de referencia 
SPAL 30.2 (2021)

74-102

ISSN: 1133-4525

ISSN-e: 2255-3924
GRUPO I

A.I.1. Ánfora

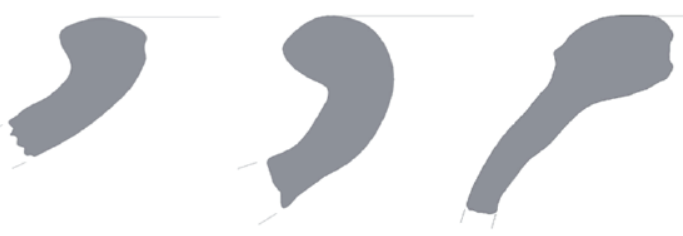

G14-60108-5

G14-60257-1

G14-60156-1

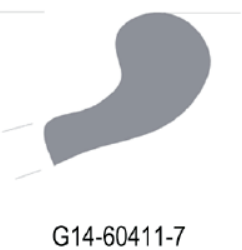

A.I.2. Tinaja
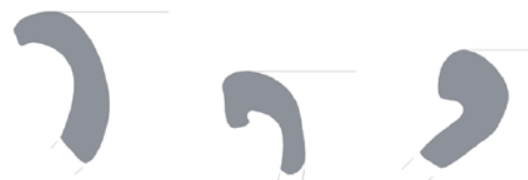

G14-60009-22 G14-60097-22

G14-60170-1

G14-60276-19

G14-60152-3

GRUPO II

A.I.2. Tinajilla

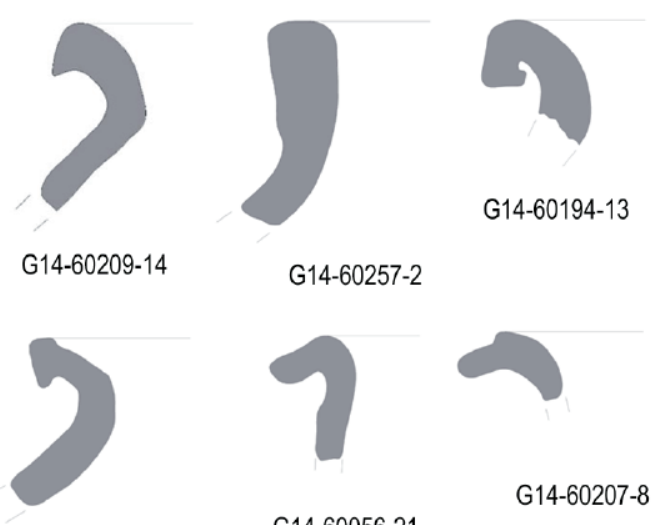

G14-60152-3

G14-60056-21
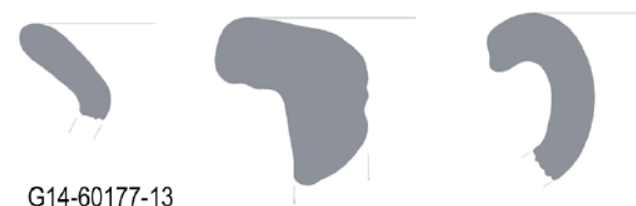

G14-60184-5

G14-60048-4

Formal 16

G14-60050-6

G14-60014-6

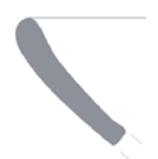

G14-6014-13

G14-60152-17

G14-60209-9

G14-60209-25

G14-60311-3

G14-60186-13

G14-60284-1

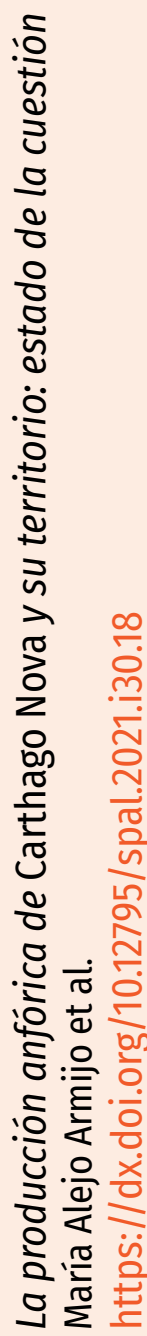

Formal 17

G14-60027-6
G14-60165-1
G14-60206-1

G14-60062-37

Cerámica gris

92

G14-60062-1

G14-60152-5 G14-60152-26

G14-60199-3

G14-60233-2

G14-60046-1

G14-60398-2

GRUPO V

G14-60209-16

Figura 13. Formas cerámicas documentadas en el área de servicio.

(Mata Parreño y Bonet Rosado, 1992), destaca con un 68\% del total el tipo A.I.2. Tinaja y A.Il.2 Tinajilla, con un diámetro comprendido entre los 10 y los $30 \mathrm{~cm}$, predominando el subtipo 2 (sin hombro) en ambas formas. La segunda categoría más numerosa es el tipo A.l.1. Ánfora, del subtipo 1, con hombro carenado. La presencia de estos vasos estáticos 
SPAL 30.2

$(2021)$

74-102

ISSN: $1133-4525$

ISSN-e: 2255-3924 viene reafirmada por el registro de dos soportes (Grupo V.2). Ambas piezas tienen un diámetro $17 \mathrm{~cm}$, pero pertenecen a individuos diferentes: uno de ellos (G14-60209-16) se incluye en el Grupo V.2.4., consignado como un soporte de carrete, de pasta anaranjada y con acanaladura central, mientras que el segundo (G14-60182-12) es de pie recto y realizado en pasta reductora. Su simple presencia muestra una clara intencionalidad de disponer algunos recipientes estáticos de grandes dimensiones en la zona Sur, próxima al Espacio 7, pudiendo destinarse al almacenaje previo a la preparación de alimentos para su posterior consumo u ofrenda en los hogares ubicados en el área de servicio, junto a la misma entrada de la cueva. De igual modo, durante el proceso de excavación se documentaron multitud de fragmentos correspondientes a un gran recipiente fabricado en pasta grosera de tono claro, esparcidos por el área central de la terraza, en las proximidades del espacio ocupado por los hogares. Otros fragmentos procesados, que corresponden a un 22\%, pertenecen a tarros, orzas pequeñas y botellas, entre otros, además de una base de cerámica grosera (G14-60405-1) de $10 \mathrm{~cm}$ de diámetro. La presencia significativa de estas formas cerradas de gran capacidad es consecuente con el fin que se le presupone al área excavada, una zona abierta destinada no a depositar ofrendas, sino a compartir actividades comunitarias, relacionadas con la preparación y el consumo de alimentos.

La cerámica se configura como el elemento mayoritario del registro y de su estudio se deduce cierta variabilidad formal y un porcentaje similar entre formas cerradas (55\%) y de tendencia abierta (45\%). En los santuarios rurales contemporáneos al de Giribaile, en el Alto Guadalquivir, tanto en la Cueva de la Lobera como en Collado de los Jardines destaca la presencia de elementos votivos, ajuares, exvotos, cerámica fina y vajilla de mesa (Rueda Galán, 2011, pp. 217-218). En contextos más avanzados, a partir del siglo I a.C., y en otro tipo de santuarios periurbanos, como el Cerro de las Norias en Las Atalayuelas (Fuerte del Rey), los conjuntos presentan una mayor heterogeneidad y variedad tipológica, con el predominio de la cerámica común, de modo que cuencos, platos, ollas, jarras, morteros y fuentes son algunas de las formas más destacadas (Rueda Galán et al., 2015), mientras que el porcentaje de grandes recipientes se reduce a tan sólo un $0,03 \%$ (Rueda Galán, 2011, pp. 217-218). En general, los datos son coincidentes con los porcentajes que cabría esperar en el registro de un lugar de culto en las cronologías antiguas de los santuarios en el territorio de Cástulo, al menos los de frontera conocidos hasta el momento.

El conjunto de registros cerámicos y faunísticos no son determinantes por sí solos sobre el carácter ritual de la terraza, interpretada como área de servicio del santuario, pero el contexto general, marcado por la presencia de los hogares a la entrada de una cueva en cuyas inmediaciones se reitera el descubrimiento continuado de exvotos parece coherente con esa posible interpretación. La presencia de altares-hogares o eschárai (Adroher et al., 1993, p. 49; Rupp, 1991, p. 303), que son aquellos que se sitúan a ras del suelo y propios de los santuarios domésticos gentilicios del Levante y Noroeste peninsular, presentan caracteristicas similares a los de Giribaile. Suelen aparecer ocupando el centro de la estancia y pueden presentar una planta circular (Puntal dels Llops, en Valencia, Alorda Park A y la Moleta de Remei 7 y 52, en Tarragona, Mas Castellar de Pontós, en Gerona), aunque frecuentemente adoptan una forma rectangular (Cerrón de Illescas, en Toledo, el Alto Chacón, en Teruel, Molí d’Espígol, en Lérida, Moleta de Remei 17 y Alorda Park D, en Tarragona, Burriac, en Barcelona) o cuadrangular como en el Castellet de Bernabé, en Valencia (Moneo Rodríguez, 2003, p. 355). También se encuentran en los santuarios del Sureste y centro peninsular, 
SPAL 30.2

$(2021)$

74-102

ISSN: $1133-4525$

ISSN-e: 2255-3924 como La Luz (Murcia), el Cerro de las Cabezas (Valdepeñas), Cancho Roano (Zalamea de la Serena) o la estancia 7b del santuario de Montemolín (Marchena, Sevilla).

La reiteración de determinados tipos de prácticas marca una acusada intención de pervivencia de la memoria de la comunidad (Margueron, 2016, p. 19), tal y como se ha mostrado a través de la disposición del CE 604 que amortiza el espacio sagrado de los fuegos rituales y, aunque la circulación en la terraza sufre una transformación profunda, el recuerdo de este espacio se mantiene vivo. No hay una intención de destruir el hogar, sino de cubrirlo con una capa de tierra (UES 6023) para construir otro. A este respecto, resulta interesante observar que un asador de hierro (G14-60227), documentado en las inmediaciones de uno de los fuegos (CE 609), fue desechado como parte del ritual, un hecho de interés para reflexionar sobre condiciones de amortización de esta área de actividad y la intención de la comunidad de dejar evidencias de la última celebración mantenida en torno al hogar. Se trataría del objeto votivo más destacado que ha podido ser documentado hasta el momento. Esta interpretación parte de la consideración de que la construcción social del rito trasciende el propio acto de consumición para generar lazos de unión entre los individuos de una misma comunidad y convertirse en una práctica cultural intrínseca a la propia sociedad (Goody, 1982; Twiss, 2007; Fernández-Götz, 2014, p. 223). El hecho de encontrar los restos de un asador, más allá de servir como instrumento para el cocinado de la carne (Principal, 2012), advierte de un contexto particular que lo dota de un carácter ritual (Almagro Gorbea y Lorrio Alvarado, 2011, p. 106), sobrepasando la función primaria por la que fue confeccionado al formar parte del depósito votivo del santuario, como instrumento litúrgico.

Finalmente, se debe hacer mención a la presencia puntual de algunas escorias de bronce dispersas, tanto en los niveles correspondientes a las fases de ocupación como desechadas entre la tierra de la UES 6023, correspondiente a un nivel de relleno. Este hecho refuerza la idea de que se trata de un área de servicio, en el que pudo practicarse puntualmente la actividad metalúrgica relacionada con la fundición de exvotos de bronce, tal y como se plantea para el sector de la cuarta terraza del santuario de Castellar (Rueda Galán, 2011), y no de un espacio dedicado a la deposición de ofrendas votivas destinadas a la divinidad.

A partir del siglo IV a.C. la dimensión ideológica y religiosa del paisaje de Cástulo se materializa a través de un proyecto de dominio territorial que se apoya en dos santuarios de frontera. La recreación del mito, que había generado una arquitectura sacra, monumental, que rememoraba al héroe en el santuario de El Pajarillo (Huelma), pasa a un segundo plano y cobra mayor peso el rito, aquellas prácticas encargadas de fomentar una cohesión e identificación social de un colectivo en el territorio, lugares sacros donde los actos de agregación socio-políticos cobran sentido (Rueda Galán y Bellón Ruiz, 2016).

\section{REFLEXIONES FINALES}

La campaña en el Área 6 de Giribaile puede considerarse como la primera intervención en un centro de culto menor en el territorio político de Cástulo. La interpretación de este lugar como santuario viene condicionada por los sucesivos hallazgos de exvotos de bronce que, supuestamente, se han producido desde la primera noticia dada a conocer por Manuel de Góngora en 1860. La excavación en la terraza no ha proporcionado 
SPAL 30.2

$(2021)$

74-102

ISSN: $1133-4525$

ISSN-e: 2255-3924

hasta el momento ninguna de estas ofrendas, hecho que no resulta extraño, aunque si una interesante sucesión de hogares a la entrada de la cueva y otra serie de evidencias que se vinculan a una posible lectura ritual. La naturaleza del registro no permite establecer zonas de actividad precisas en el área de servicio del santuario, aunque sí proporciona un asador, restos faunísticos y conjuntos de cerámicas que serían compatibles con la celebración de banquetes. Además, las construcciones dispuestas en torno a los hogares, tal vez se correspondieran con bancos que permitían sentarse a los miembros de la comunidad para compartir la comida y el resto de actos litúrgicos que se celebraban bajo el gran bloque de piedra, hoy caído a la entrada de la cueva. La caracterización de estos espacios, localizados en la propia entrada que da acceso al santuario, resulta de un gran interés para comprender las acciones normalizadas de comensalidad ritual previas a una supuesta deposición de las ofrendas en el interior de la cueva. En el caso concreto de Giribaile, además hay que tener en cuenta que la comunidad estaba conformada de forma conjunta por los habitantes que vivían dentro del recinto fortificado de la meseta más todas aquellas personas diseminadas en asentamientos estables en el valle.

Resulta interesante observar el cuidado con el que se realizan las sucesivas reformas en este espacio, manifestando la intención de no destruir los hogares. Así, la capa de tierra (UES 6023) que actúa como interfaces entre las fases II y III del santuario amortiza la placa de hogar CE 609 y la memoria del rito (CE 604) perpetúa este signo de identidad a la entrada de la cueva. Finalmente, la transformación de la estructura del acceso al santuario hacia un espacio abierto que amortiza el antiguo concepto de terraza delimitada por un temenos es coherente con el creciente proceso de implantación de sistemas ciudadanos que se manifiesta en la proliferación de los exvotos individuales ofrecidos a la divinidad en los santuarios extraterritoriales del territorio de Cástulo. Aunque resulta difícil precisar el tiempo exacto de esta modificación arquitectónica, el cambio también podría interpretarse como una temprana transformación ideológica, consecuencia de la primera implantación del dominio romano en el territorio. Sólo nuevas campañas de excavación permitirán conocer en mayor profundidad la fase inicial del santuario y ampliar el área de trabajo en el frente exterior de la cueva, factores, sin duda, determinantes para completar el análisis y estudio de la cueva santuario de Giribaile.

\section{Agradecimientos}

Proyecto de investigación Innovaciones técnicas aplicadas al conocimiento y puesta en valor de Giribaile (P11-HUM-8113), financiado por la Junta de Andalucía a cargo de los Incentivos a Proyectos de Investigación de Excelencia en equipos de investigación, dentro de la Modalidad Proyectos Motrices y de Innovación.

\section{BIBLIOGRAFÍA}

Abad Casal, L. y Sala Selles, F. (1993) El poblado ibérico de El Oral (San Fulgencio, Alicante). Serie de Trabajos Varios, 90. Valencia: Servicio de Investigación Prehistórica. Diputación Provincial de Valencia. 


\section{SPAL 30.2 $(2021)$}

\section{4-102}

ISSN: 1133-4525 ISSN-e: 2255-3924
Adroher Auroux, A.M., Pons i Brun, E. y Ruiz de Arbulo, J. (1993) “El yacimiento de Mas Castellar de Pontós y el comercio del cereal ibérico", Archivo Español de Arqueología, 66, vol. 167-168, pp. 31-70. https://doi.org/10.3989/aespa.1993.v66.459

Adroher Auroux, A.M., Carreras Monfort, C., De Almeida, R., Fernández Fernández, A., Molina Vidal, J. y Viegas, C. (2016) “Registro para la cuantificación de cerámica arqueológica: estado de la cuestión y una nueva propuesta. Protocolo de Sevilla (prcs/14)", Zephyrus, 78, pp. 87-110.

Almagro Gorbea, M. (1999) "Los íberos en Castilla-La Mancha", en Valero Tévar, M.Á. (ed.) Primeras Jornadas de Arqueología Ibérica en Castilla-La Mancha. Cuenca 1997. Toledo: Junta de Comunidades de Castilla-La Mancha, Consejería de Educación y Cultura, pp. 25-48.

Almagro Gorbea, M. y Lorrio Alvarado, A.J. (2011) Teutates: el héroe fundador y el culto heróico al antepasado en Hispania y en la Keltike. Madrid: Real Academia de la Historia.

Aparicio Pérez, J. (1997) “El culto en cuevas y la religiosidad protohistórica”, Quaderns de Prehistòria i Arqueologia de Castelló, 18, pp. 345-358.

Armada Pita, X. L. (2015) “Sacrificio, consumo cárnico y religión del Bronce Atlántico a los celtas occidentales”, en García Fenández, F.J., Lozano Gómez, F. y Pereira Delgado, Á. (eds.) El alimento de los dioses. Sacrificio y consumo de alimentos en las religiones antiguas, Spal, 20. Sevilla: Universiad de Sevilla, pp. 123-156.

Battini, L. (2015) "How better understanding of ritual practices can help the comprehension of religious feelings", en Laneri, N. (ed.) Defining the sacred: approaches to the archaeology of religion in the Near East. Reino Unido y Estados Unidos: Oxbow Books, pp. 176-183. https:// doi.org/10.3764/ajaonline1211.Ameri

Bea Castaño, D., Diloli Fons, J. y Vilaseca Cañáis, A. (2004) “Espacio religioso y/o espacio de poder: el yacimiento protohistórico de «El Turó del Calvari» (Vilalba dels Arcs, Terra Alta, Tarragona)", en Alvar, J. y Hernández Guerra, L. (eds.) Jerarquías religiosas y control social en el mundo antiguo: Actas del XXVII Congreso Internacional Girea-Arys IX. Valladolid 2002. Valladolid: Universidad de Valladolid, Secretariado de Publicaciones e Intercambio Editorial, pp. 51-62.

Belén, M. y Escacena, J.L. (1997) "Testimonios religiosos de la presencia fenicia en Andalucía Occidental”, Spal, 6, pp. 103-132. Accesible en: https://dialnet.unirioja.es/servlet/articulo?codigo $=635833$ (consultado 8 mayo 2016)

Benítez de Lugo Enrich, L. y Moraleda Sierra, J. (2013) "Símbolos, espacios y elementos ibéricos para el culto en la Oretania Septentrional. Estado de la cuestión arqueológica, revisión crítica y nuevas aportaciones", en Rísquez Cuenca, C. y Rueda Galán, C. (eds.) Santuarios iberos: territorio, ritualidad y memoria. Actas del Congreso "El Santuario de la Cueva de la Lobera de Castellar. 1912-2012". Castellar 2012. Torredonjimeno: Asociación para el Desarrollo Rural de la Comarca de El Condado, pp. 213-270. Accesible en: https://www.academia. edu/5818794/Santuarios_Iberos_territorio_ritualidad_y_memoria_Actas_del_Congreso_El_ santuario_de_la_Cueva_de_la_Lobera_de_Castellar_Ja\%C3\%A9n_1912_2012 (consultado 15 abril 2016)

Bonet Rosado, H. (2013) "Contextos arqueológicos de los textos ibéricos valencianos" en Ballester, X., Beltrán Lloris, F., Fernández Nieto, F.J., Jordán Cólera, C., Siles, J. (eds.) Acta Palaeohispanica XI. Actas del coloquio internacional de lenguas y cultura prerromanas de la Península Ibérica, Palaeohispanica, 13. Valencia, 2012. Zaragoza: IFC - Acadèmia Valenciana de la Llengua, pp. 387-406.

Broncano Rodríguez, S. y Alfaro Arregui, M. del M. (1993) "Estado actual de las excavaciones arqueológicas en El Amarejo", en Blánquez, J., Sanz Gamo, R. y Musat Hervás, M.T. (eds.) Arqueología en Albacete: Jornadas de Arqueología Albacetense en la Universidad Autónoma de Madrid. Albacete 1983. Madrid: Junta de Comunidades de Castilla-La Mancha, pp. 131-144.

Castelo Ruano, R. (1995) Monumentos funerarios del sureste peninsular: elementos y técnicas constructivas. Madrid: Universidad Autónoma de Madrid.

Cazorla Martín, R. y Celestino Pérez, S. (2008) "La Cueva del Valle (Zalamea de La Serena, Badajoz): un santuario rupestre en la comarca de La Serena”. Spal, 17, pp. 207-231. 


\section{SPAL 30.2 $(2021)$}

\section{4-102}

ISSN: $1133-4525$ ISSN-e: 2255-3924
Celestino Pérez, S. (2001) "Los santuarios de Cancho Roano. Del indigenismo al orientalismo arquitectónico", en Ruiz Mata, D. y Celestino Pérez, S. (coords.) Arquitectura Oriental y Orientalizante en la península ibérica. Madrid: Consejo Superior de Investigaciones Científicas, Instituto de Historia, pp. 17-56.

Chaves Tristán, F. y de la Bandera Romero, M.L. (1984) “Avance sobre el yacimiento arqueológico de Montemolín (Marchena, Sevilla)", en Blagg, T.F.C., Jones, R.F. y Keay, S.J. (eds.) Papers in Iberian Archaeology, B.A.R. International Series, 193. Oxford: Archaeopress, pp. 141-186.

Chaves Tristán, F., de la Bandera Romero, M.L., Ferrer Albelda, E. y Bernáldez Sánchez, E., (1995) "El yacimiento tartésico de Montemolín. Tartessos 25 años después (1968-1993)", Tartessos: 25 años después, 1968-1993. Actas del Congreso Conmemorativo de V Symposium Internacional de Prehistoria Peninsular. Jerez de la Frontera 1993. Jerez de la Frontera: Ayuntamiento de Jerez de la Frontera, pp. 315-332.

De Polignac, F. (1995) Cults, territory, and the origins of the Greek city-state. Chicago: University of Chicago Press.

Delougaz, P. y Lloyd, S. (1942) Pre-sargonid temples in the Diyala region. Chicago: University of Chicago Press.

Dietler, M. y Hayden, B. (eds.) (2001) Feasts: archaeological and etnographic perspectives on food, politics and power. Washingon: Smithsonian Institution.

Domergue, C. (1987) Catalogue des mines et des fonderies antiques de la Péninsule Ibérique. Collection de la Casa de Velázquez, 23. Madrid: Casa de Velázquez.

Domergue, C. (1990) “Les mines de la Péninsule Ibérique dans l'Antiquité Romaine". Publications de l'École française de Rome, 127. Rome: École Française de Rome.

Ekroth, G. (2014) "Animal sacrifice in Antiquity", en Campbell, G.L. (ed.) The Oxford Handbook of Animals in Classical Thought and Life. Oxford: OUP Oxford. https://doi.org/10.1093/ oxfordhb/9780199589425.001.0001

Fernández-Götz, M. (2014) Identity and power: the transformation of Iron Age societies in Northeast Gaul. Amsterdam: Amsterdam University Press.

Ginouves, R. y Guimier-Sorbets, A.-M. (1991) "Les autels de l'antiquite classique: problemes de description", en Etienne, R.y le Dinahet, M.-T. (eds.) L'espace sacrificiel dans les civilisations Méditerranéenes de l'Antiquité. Actes du Colloque tenu à la Maison de l'Orient. Publications de la Bibliothèque Salomon Reinach, 5. Lyon 1988. Paris: Diffusion de Boccard, pp. 277-290.

Góngora y Martínez, M. (1860) "Viaje literario por las provincias de Granada y Jaén", Don Lope de Sosa 1915-1916. Crónica mensual de la provincia de Jaén, pp. 5-8 y 38-39.

Goody, J. (1982) Cooking, Cuisine and Class. A Study in Comparative Sociology. Nueva York: Cambridge University Press. https://doi.org/10.1002/food.19840280214

Grau Mira, I. (1996) “Estudio de las excavaciones antiguas de 1953 y 1956 en el poblado ibérico de la Serreta" Recerques del Museu d'Alcoi, 5, pp. 83-119.

Grau Mira, I. y Amorós López, I. (2013) "La delimitación simbólica de los espacios territoriales ibéricos: el culto en el confín y las cuevas-santuario", en Rísquez Cuenca, C. y Rueda Galán, C. (eds.) Santuarios iberos: territorio, ritualidad y memoria. Actas del Congreso "El Santuario de la Cueva de la Lobera de Castellar. 1912-2012". Castellar 2012. Torredonjimeno: Asociación para el Desarrollo Rural de la Comarca de El Condado, pp. 183-211. https://www.academia. edu/5818794/Santuarios_Iberos_territorio_ritualidad_y_memoria_Actas_del_Congreso_El_ santuario_de_la_Cueva_de_la_Lobera_de_Castellar_Ja\%C3\%A9n_1912_2012 (consultado 20 abril 2016)

Gutiérrez Soler L.M. (2002): El «oppidum» de Giribaile. Jaén: Servicio de Publicaciones de la Universidad de Jaén.

Gutiérrez Soler L.M. (2009), “Giribaile, nuestra pequeña Pompeya una ciudad ibérica en el corazón de la Oretania", Andalucía en la Historia, 24, pp. 94-98.

Gutiérrez Soler L.M. (2010) “Microprospección arqueológica en Giribaile (Vilches, Jaén). Protocolo de trabajo", Trabajos de Prehistoria, 67 (1), pp. 7-35. Accesible en: http://tp.revistas.csic.es/ index.php/tp/article/view/182/182 (consultado 20 noviembre 2019) https://doi.org/10.3989/ tp.2010.10029 


\section{SPAL 30.2 $(2021)$}

\section{4-102}

ISSN: $1133-4525$ ISSN-e: 2255-3924
Gutiérrez Soler L.M., Royo Encarnación, M.A., Barba Colmenero, V. y Bellón Ruiz, J.P. (1995) “Informe sobre la primera campaña de prospección arqueológica superficial en el Guadalimar medio-hinterland de Cástulo", Anuario Arqueológico de Andalucía 1992, II. Sevilla: Junta de Andalucía, Consejería de Cultura, Dirección General de Bienes Culturales, D. L., pp. 249-256.

Gutiérrez Soler L.M., Royo Encarnación, M.A., Barba Colmenero, V. y Bellón Ruiz, J.P. (1999) “Informe de la segunda campaña de prospección superficial en el Guadalimar medio-hinterland de Cástulo", Anuario Arqueológico de Andalucía de 1994, II. Sevilla: Junta de Andalucía, Consejería de Cultura, Dirección General de Bienes Culturales, D. L., pp. 113-118.

Halstead, P. e Isaakidou, V. (2004) "Faunal evidence for feasting: burnt offerings from the palace of Nestor at Pylos", Food, Cuisine and Society in Prehistoric Greece, Sheffield Studies in Aegean Archaeology, 5. Reino Unido y Estados Unidos: Oxbow Books, pp. 136-154. https://doi. org/10.2307/j.ctvh1drns.11

Henson, D. (2011) “Does archaeology matter?" en Moshenska, G. y Dhanjal, S. (eds.) Community Archaeology. Themes, methods and practices. Oxford: Oxbow book, pp. 120-127. https://doi. org/10.2307/j.ctvh1dn3q

Homero, La Odisea, Calvo Martínez, J.L. (ed.) (2006) Colección Letras Universales. Madrid: Cátedra. Kaliff, A. (2011) "Fire", en Insoll, T. (ed.) The Oxford Handbook of the Archaeology of Ritual and Religion. Nueva York: Oxford University Press, pp. 51-60. https://doi.org/10.1093/ oxfordhb/9780199232444.001.0001

Lafond, Y. y Michel, V. (2016) Espaces sacrés dans la Méditerranée Antique: Actes du Colloque des 13 et 14 octobre 2011. Collection Histoire, 359. Poitiers 2011. Rennes: Presses Universitaires de Rennes.

Laneri, N. (2015) "Introduction: Investigating archaeological approaches to the study of religious practices and beliefs", en Laneri, N. (ed.) Defining the sacred: approaches to the archaeology of religión in the Near East. Reino Unido y Estados Unidos: Oxbow Books, pp. 1-10. https:// doi.org/10.3764/ajaonline1211.Ameri

Margueron, J.C. (2016) “Entre profane et sacré: y a-t-il des degrés dans la sacralisation de l'espace mésopotamien (IVer-ler millénaire av. J.-C.)?”, en Lafond, Y. y Michel, V. (eds.) Espaces sacrés dans la Méditerranée Antique: Actes du Colloque des 13 et 14 octobre 2011. Collection Histoire, 359. Poitiers 2011. Rennes: Presses Universitaires de Rennes, pp. 15-57.

Mata Parreño, C. y Bonet Rosado, H. (1992) "La cerámica ibérica: ensayo de tipología", Estudios de Arqueología Ibérica y Romana: Homenaje a Enrique Pla Ballester, Serie de Trabajos Varios, 89. Valencia: Servicio de Investigación Prehistórica. Diputación Provincial de Valencia, pp. 117-174. Accesible en: http://www.museuprehistoriavalencia.es/web_mupreva_dedalo/ publicaciones/120/es (consultado 5 marzo 206).

Moneo Rodríguez, T. (2003) Religio Iberica. Santuarios, ritos y divinidades (siglos VII-I a.C.). Madrid: Real Academia de la Historia.

Moreno García, M. (2011) “Las ofrendas votivas de origen animal”, en Rueda Galán, C., Sánchez Vizcaíno, A., Parras Guijarro, D.J., Ramos Martos, N. y Moreno García, M. (col.) Territorio, culto e iconografía en los santuarios iberos del Alto Guadalquivir (ss. IV a.n.e.-I d.n.e.). Jaén: Servicios de Publicaciones de la Universidad de Jaén, pp. 227-230.

Negroni Catacchio, N., Cardosa, M., Guidetti, L. y Miari, M. (2002) "Holy fires and profane fires in protohistoric Etruria. New data from the settlement of sorgenti della Nova (Viterbo-Italy)", en Gheorghiu, D. (ed.) Fire in archaeology. Papers from a session held at the European Association of Archaeologists Sixth Annual Meeting in Lisbon 2000. BAR International Series, S1089. Lisboa 2000. Oxford: Archaeopress, pp. 115-125. https://doi.org/10.30861/9781841714677

Nicolini, G. (1969) "Les bronzes figurés des sanctuaires ibériques", Bibliothéque de l'École des Háutes Etudes Hispaniques, XLI. París: Presses universitaires.

Nicolini, G., Rísquez, C., Ruiz, A. y Zafra, N. (2004), "El santuario ibérico de Castellar, Jaén. Intervenciones arqueológicas 1966-1991”, Arqueología. Serie Monografías, 18. Sevilla: Junta de Andalucía.

Niveau de Villedary y Mariñas, A.M. (2003) “El uso ritual de la vajilla cerámica en la necrópolis púnica de Cádiz", Archivo Español de Arqueología, 76, pp. 3-30. Accesible en http://aespa. 


\section{SPAL 30.2 $(2021)$}

\section{4-102}

ISSN: 1133-4525 ISSN-e: 2255-3924

revistas.csic.es/index.php/aespa/article/view/103/101 (consultado 15 junio 2018). https:// doi.org/10.3989/egeogr.2001.i245.267

Ocharán Ibarra, J.Á. (2017) Santuarios rupestres ibéricos del sureste peninsular. Tesis Doctoral. Universitat d'Alacant - Universidad de Alicante (España). Accesible en: http://hdl.handle. net/10045/74633 (consultado 16 mayo 2018).

Ortiz Villarejo, A.J., Gutiérrez Soler, L.M., Alejo Armijo, M. y Gutiérrez Rodríguez, M. (2020a) "Estabulación, almacenaje y alimentación durante los siglos IV-III a.C. en el Área 3 de Giribaile", Historia Agraria, 82, pp. 1-36. Accesible en: http://historiaagraria.com/en/issues/antonio_ jesus_ortiz_villarejo_luis_maria_gutierrez_soler_maria_alejo_armijo_mario_gutierrez_rodrigue-estabulacion_almacenaje_y_alimentacion_durante_los_siglos_iv-iii_a_c_en_el_ area_3_de_giribaile (consultado 17 mayo 2020). http://doi.org/10.26882/histagrar.082e06o

Ortiz Villarejo, A.J., Gutiérrez Soler, L.M. y Alejo Armijo, M. (2020b) “El Área 11 de Giribaile: estructura arquitectónica y materiales de construcción de un almacén ibérico de los siglos IV-II a.C.", Archivo Español de Arqueología, 93, pp. 81-101. Accesible en: http://aespa.revistas.csic.es/index.php/aespa/article/view/565 (consultado 10 octubre 2020). https://doi. org/10.3989/aespa.093.020.004

Pereira Sieso, J. (1988) "La cerámica ibérica de la cuenca del Guadalquivir (I). Propuesta de clasificación", Trabajos de Prehistoria, 45 (I), pp. 143-174. Accesible en: https://dialnet.unirioja. es/servlet/articulo?codigo=258239 (consultado 15 marzo 2016)

Principal, J. (2012) “A comer! Comida y comensales en el mundo ibérico”, en Flores Barrio, C. y Gandullo de Tapia, L. (eds.) Iberos. Sociedades y territorios del occidente mediterráneo. Madrid: Consejo Superior de Investigaciones Científicas, pp. 143-161.

Ramos Fernández, R. y Ramos Molina, A. (1992) El monumento y el "temenos" ibérico del Parque de Elche. Elche: Ayuntamiento de Elche.

Rísquez Cuenca, C., Rueda Galán, C., Nicolini, G., Ruiz Rodríguez, A., Zafra, N. y Esteban, C. (2015) "El santuario de la Cueva de La Lobera" en Ruiz Rodríguez, A. y Molinos Molinos, M. (coords.) Jaén, tierra íbera. 40 años de investigación y transferencia. Jaén: Servicios de Publicaciones de la Universidad de Jaén, pp. 205-221.

Rodríguez Ariza, M.O. (2007) "Análisis antracológico de la Cámara de Hornos", en Molinos Molinos, M. y Ruiz Rodríguez, A. (coords.) El hipogeo ibero del Cerrillo de la Compañía de Hornos (Peal de Becerro, Jaén). Jaén: Servicios de Publicaciones de la Universidad de Jaén, pp. 91-98.

Rodríguez González, E. (2017) "Las estancias de los dioses: la habitación 100 del yacimiento de Casas del Turuñuelo (Guareña, Badajoz)", Cuadernos de Prehistoria y Arqueología de la Universidad Autónoma de Madrid, 43, pp. 179-194. Accesible en: https://revistas.uam. es/cupauam/article/view/9040 (consultado 10 noviembre 2020). https://doi.org/10.15366/ cupauam2017.43.006

Rueda Galán, C. (2011) Territorio, culto e iconografía en los santuarios iberos del Alto Guadalquivir: s. IV a.n.e.-I d.n.e. Jaén: Servicios de Publicaciones de la Universidad de Jaén.

Rueda Galán, C. (2012) "Paseando descalzos por un santuario ibero", en González Reyero, S. (ed.) Iberos. Sociedades y territorios del occidente mediterráneo. Madrid: Consejo Superior de Investigaciones Científicas, pp. 175-186.

Rueda Galán, C., Gutiérrez Soler, L.M. y Bellón Ruiz, J.P. (2008) “Aportación desde los procesos territoriales a las lecturas iconográficas de los santuarios del Alto Guadalquivir", Anales de Arqueología Cordobesa, 19. Córdoba: Universidad de Córdoba, pp. 23-47.

Rueda Galán, C., Molinos Molinos, M. y Ruiz Rodríguez, A. (2015) “Culto, rito y ofrenda en el santuario periurbano de Las Atalayuelas (Fuerte del Rey)", en Ruiz Rodríguez, A. y Molinos Molinos, M. (coords.) Jaén, tierra íbera. 40 años de investigación y transferencia. Jaén: Servicios de Publicaciones de la Universidad de Jaén, pp. 423-436.

Rueda Galán, C. y Bellón Ruiz, J.P. (2016) “Culto y rito en cuevas: modelos territoriales de vivencia y experimentación de lo sagrado, más allá de la materialidad (ss. V-II a.n.e.)", Arys. Antigüedad: religiones y sociedades, 14, pp. 43-80. Accesible en: https://e-revistas.uc3m. es/index.php/ARYS/article/view/3986 (consultado 17 junio 2018) https://doi.org/10.20318/ arys.2017.3986 


\section{SPAL 30.2 $(2021)$}

\section{4-102}

ISSN: $1133-4525$ ISSN-e: 2255-3924
Ruiz Rodríguez, A. y Rueda Galán, C. (2014) "Los exvotos en bronce del Farmm: oppida y santuarios instrumentos líticos", en Junta de Andalucía. Consejería de Educación, Cultura y Deporte (ed.), FARMM. Fondo Arqueológico Ricardo Marsal Monzón. Sevilla: Consejería de Educación, Cultura y Deporte, pp. 131-144. Accesible en: https://www.juntadeandalucia.es/ export/drupaljda/Marsalfinal.pdf (consultado 8 mayo 2016).

Ruiz Rodríguez, A., Rueda Galán, C., Bellón Ruiz, J.P. y Gómez Cabeza, F. (2013) “El factor íbero en la batalla de Baécula: los efectos colaterales de la guerra", Cuadernos de Prehistoria y Arqueología de la Universidad de Granada, 23, pp. 199-225. Accesible en: https:// revistaseug. ugr.es/index.php/cpag/article/view/3108 (consultado 1 octubre 2020).

Ruiz Rodríguez, A., Molinos Molinos, M., Fernández, R., Pérez Gutiérrez, M. y Rueda Galán, C. (2015) "El santuario de la Puerta del Sol", en Ruiz Rodríguez, A. y Molinos Molinos, M. (coords.) Jaén, tierra íbera. 40 años de investigación y transferencia. Jaén: Servicios de Publicaciones de la Universidad de Jaén, pp. 93-106.

Rupp, D.W. (1991) "The altars of southern Greece: a typological analysis", en Étienne, R. y Le Dinahet, M.T. (eds.) L'espace sacrificiel dans les civilisations méditerranéenes de l'antiquité. Actes du Colloque tenu à la Maison de l'Orient. Publications de la Bibliothèque Salomon Reinach, 5. Lyon 1988. Paris: Diffusion de Boccard, pp. 303-306.

Seco Serra, I. (2010) "Santuarios betílicos en la Protohistoria peninsular. El caso de San Miguel de Liria", en Tortosa Rocamora, T., Celestino Pérez, S. y Cazorla Martín, R. (eds.) Debate en torno a la religiosidad protohistórica. Madrid: Consejo Superior de Investigaciones Científicas, pp. 169-176.

Tortosa Rocamora, T., Haber Uriarte, M., Comino Comino, A. y Avilés Fernández, A. (2018) “El santuario de la Luz (Santo Ángel, Murcia) hombre, fauna y ritual” en Ferrer Albelda, E. y Navarro Ortega, A.D. (coords.) Trabajo sagrado: producción y representación en el Mediterráneo Occidental durante el I milenio a.C., Spal, 25. Sevilla: Universidad de Sevilla, pp. 309-328.

Twiss, K.C. (2007) The archaeology of food and identity, Occasional paper, 34. Carbondale: Center for Archaeological Investigations.

Valiente Cánovas, S. (1994) Illescas: excavaciones arqueológicas en «El Cerrón», Illescas (Tole- 


\section{ANEXO TABLAS}

Tabla 1. Estudio antracológico. Taxones identificados en la campaña de excavación en el Área 6.

\begin{tabular}{|c|c|c|c|c|c|c|c|c|c|c|c|c|c|c|c|c|c|c|c|c|c|}
\hline \multicolumn{22}{|c|}{ Giribaile 2014} \\
\hline \multicolumn{22}{|c|}{ Área 6 (Cueva-Santuario) } \\
\hline Cronología & \multicolumn{3}{|c|}{ Fase 1} & Interfaz & \multicolumn{2}{|c|}{ Fase 2} & \multicolumn{5}{|c|}{ Interfaz } & \multicolumn{4}{|c|}{ Fase 3} & \multicolumn{6}{|c|}{ Niveles postibéricos } \\
\hline UEN & \multicolumn{2}{|c|}{6068} & \multirow{2}{*}{$\begin{array}{c}6078 \\
60386\end{array}$} & \multirow{2}{*}{$\begin{array}{c}6083 \\
60382\end{array}$} & \multirow{2}{*}{$\begin{array}{r}6065 \\
60270\end{array}$} & \multirow{2}{*}{$\begin{array}{l}6082 \\
60370\end{array}$} & \multicolumn{3}{|c|}{6023} & \multirow{2}{*}{$\begin{array}{l}6043 \\
60254\end{array}$} & \multirow{2}{*}{$\begin{array}{l}6080 \\
60424\end{array}$} & \multicolumn{2}{|c|}{6008} & \multirow{2}{*}{$\begin{array}{l}6034 \\
60119\end{array}$} & \multirow{2}{*}{$\begin{array}{l}6035 \\
60120\end{array}$} & \multirow{2}{*}{$\begin{array}{l}6003 \\
60031\end{array}$} & \multirow{2}{*}{$\begin{array}{l}6010 \\
60093\end{array}$} & \multirow{2}{*}{$\begin{array}{c}6013 \\
60106\end{array}$} & \multirow{2}{*}{$\begin{array}{r}6026 \\
60085\end{array}$} & \multirow{2}{*}{$\frac{6027}{60086}$} & \multirow{2}{*}{$\begin{array}{r}6028 \\
60087\end{array}$} \\
\hline № Inventario & 60274 & 60275 & & & & & 60354 & 60417 & 60423 & & & 60091 & 60094 & & & & & & & & \\
\hline Arbutus unedo & - & - & 4 & - & - & - & - & - & - & - & - & - & - & - & - & - & 2 & - & - & - & - \\
\hline Fraxinus sp. & - & - & - & - & - & - & - & - & - & - & - & 4 & - & - & - & - & 4 & 3 & - & & 7 \\
\hline Olea europea & - & 2 & - & 5 & 2 & 25 & 3 & - & 8 & 22 & - & - & 6 & 2 & 13 & 2 & 5 & 7 & 5 & 19 & 11 \\
\hline Phillyrea sp. & - & - & - & - & - & 1 & - & - & - & - & - & 1 & - & - & - & - & - & 1 & - & - & 1 \\
\hline Pinus sp. & - & - & - & - & - & - & - & - & - & - & - & - & - & - & - & - & - & 1 & - & - & - \\
\hline Pistacia lentiscus & 5 & 4 & 9 & 13 & 3 & 12 & 1 & 3 & - & 7 & 15 & - & - & 12 & 16 & - & - & 9 & - & - & - \\
\hline Prunus dulcis & - & - & - & 4 & - & 1 & 6 & - & - & - & - & - & - & 1 & 8 & - & 2 & 21 & - & - & 1 \\
\hline Quercus iles/coccifera & - & - & - & 4 & 4 & - & 5 & - & - & - & - & 1 & - & 2 & - & 2 & 3 & 4 & - & - & 5 \\
\hline Indeterminables & - & 1 & - & 2 & 1 & 1 & 1 & - & - & - & - & - & - & 2 & - & 1 & 2 & 3 & - & - & 1 \\
\hline TOTAL CARBONES & 5 & 7 & 13 & 28 & 10 & 40 & 16 & 3 & 8 & 29 & 15 & 6 & 6 & 19 & 37 & 5 & 18 & 49 & 5 & 19 & 26 \\
\hline TOTAL TAXONES & 1 & 2 & 2 & 4 & 3 & 4 & 4 & 1 & 1 & 2 & 1 & 3 & 1 & 4 & 3 & 2 & 5 & 7 & 1 & 1 & 5 \\
\hline
\end{tabular}

Tabla 2. Estudio faunístico. Restos identificados en la campaña de excavación en el Área 6.

\begin{tabular}{|c|c|c|c|c|c|c|c|c|c|c|c|c|c|c|c|c|c|c|c|c|c|c|c|}
\hline \multicolumn{24}{|c|}{ Giribaile 2014} \\
\hline \multicolumn{24}{|c|}{ Área 6 (Cueva-Santuario) } \\
\hline \multicolumn{2}{|c|}{ Cronología } & \multicolumn{3}{|c|}{ Fase 1} & \multirow{3}{*}{$\begin{array}{c}\text { Interfaz } \\
6083 \\
60381\end{array}$} & \multirow{3}{*}{$\begin{array}{c}\text { Fase } 2 \\
6065 \\
60268\end{array}$} & \multicolumn{6}{|c|}{ Interfaz } & \multirow{3}{*}{$\begin{array}{l}\text { Fase } 3 \\
\text { ESP } 7 \\
60395\end{array}$} & \multicolumn{10}{|c|}{ Niveles postibéricos } \\
\hline \multicolumn{2}{|l|}{ UEN } & 6071 & 6076 & 6077 & & & \multicolumn{3}{|c|}{6023} & \multicolumn{3}{|c|}{6042} & & \multicolumn{2}{|c|}{6024} & \multicolumn{2}{|c|}{6033} & \multicolumn{2}{|c|}{6025} & 6044 & \multicolumn{2}{|c|}{6041} & \\
\hline № Inventario & & 60300 & 60355 & 60357 & & & 60158 & 60263 & 60279 & 60322 & 60324 & 60329 & & 60145 & 60073 & 60107 & 60131 & 60114 & 60101 & 60174 & 60224 & 60226 & 60385 \\
\hline \multirow{9}{*}{ Ovicaprino } & Radio & - & - & - & - & - & - & - & - & - & - & - & - & - & 1 & - & - & 1 & - & - & - & - & - \\
\hline & Tibia & - & 2 & - & - & - & - & - & - & - & - & - & - & - & - & - & - & & 2 & 1 & - & - & - \\
\hline & Mandibula & - & - & 1 & - & - & - & - & - & - & - & - & 1 & - & - & 1 & - & - & - & - & - & - & - \\
\hline & Húmero & - & - & - & - & - & - & - & - & - & - & - & - & - & - & 1 & - & - & - & - & - & - & - \\
\hline & Metatarso & - & - & - & - & - & - & - & - & - & - & - & - & - & - & 1 & 1 & - & - & - & - & - & - \\
\hline & Costillas & - & - & - & - & - & 1 & - & 1 & - & - & - & - & - & - & - & - & - & - & - & - & - & - \\
\hline & Fémur & - & - & - & - & - & 1 & - & - & - & - & - & - & - & - & - & - & - & - & - & - & - & - \\
\hline & Diente inferior & - & - & - & - & 1 & - & - & - & - & - & - & - & - & - & - & - & - & - & - & - & - & - \\
\hline & Calcáneo & - & - & - & - & - & - & - & - & - & - & 1 & - & - & - & - & - & - & - & - & - & - & - \\
\hline \multirow[t]{3}{*}{ Cerdo } & Mandíbula & 1 & - & - & - & - & - & - & - & - & - & - & - & - & - & - & 1 & - & - & - & - & - & - \\
\hline & Ulna & - & - & - & - & - & - & - & - & - & - & - & - & 1 & - & - & - & - & - & - & - & - & \\
\hline & Diente superior & - & - & - & - & - & - & - & - & - & - & - & - & - & - & - & - & - & - & - & - & - & 1 \\
\hline Oveja & Tibia & - & - & - & - & - & - & - & - & 1 & - & - & - & - & - & - & - & - & - & - & - & - & \\
\hline Cabra & Calcáneo & - & - & - & - & - & - & 1 & - & - & - & - & - & - & - & - & - & - & - & - & - & - & - \\
\hline H. Humanos & & - & - & - & - & - & - & - & - & - & - & - & - & - & - & - & - & - & - & 1 & 1 & - & - \\
\hline Indeterminado & & - & - & 1 & 1 & - & - & - & 1 & 1 & 1 & - & - & - & 1 & - & - & 1 & 1 & - & - & - & - \\
\hline
\end{tabular}


SPAL 30.2 (2021)

\section{4-102}

ISSN: $1133-4525$

ISSN-e: 2255-3924
Tabla 3. Representación de los grupos cerámicos diferenciados por fases, atendiendo al número de bordes estudiados.

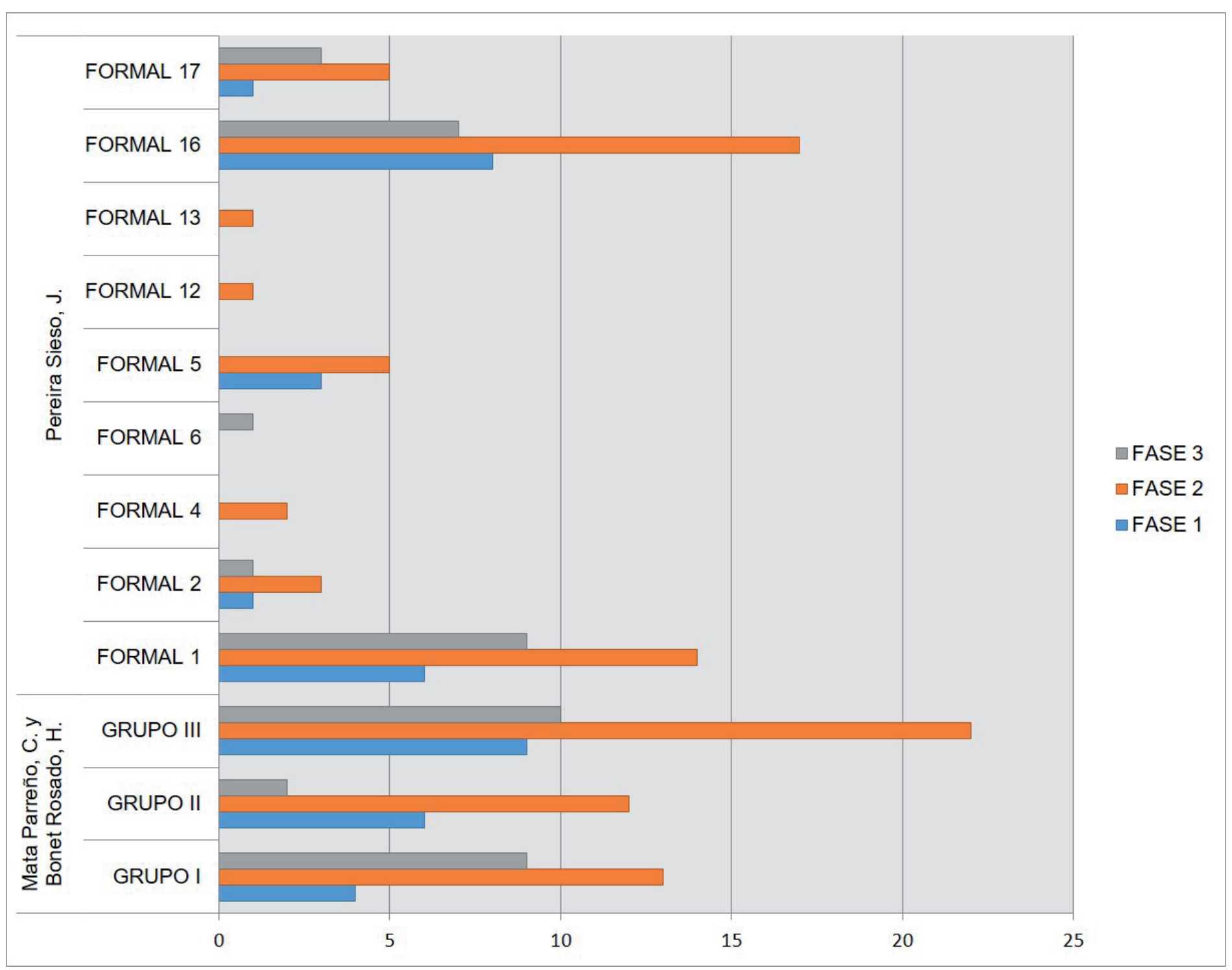

